\title{
Stealth Nanoparticles Grafted with Dense Polymer Brushes Display Adsorption of Serum Protein Investigated by Isothermal Titration Calorimetry
}

\author{
Noga Gal, Martina Schroffenegger, and Erik Reimhult*(i) \\ Institute for Biologically Inspired Materials, Department of Nanobiotechnology, University of Natural Resources and Life Sciences \\ Vienna, Muthgasse 11-II, A-1190 Vienna, Austria
}

Supporting Information

\begin{abstract}
Core-shell nanoparticles receive much attention for their current and potential applications in life sciences. Commonly, a dense shell of hydrated polymer, a polymer brush, is grafted to improve colloidal stability of functional nanoparticles and to prevent protein adsorption, aggregation, cell recognition, and uptake. Until recently, it was widely assumed that a polymer brush shell indeed prevents strong association of proteins and that this leads to their superior "stealth" properties in vitro and in vivo. We show using $T$-dependent isothermal titration calorimetry on well-characterized monodisperse superparamagnetic iron oxide nanoparticles with controlled dense stealth polymer

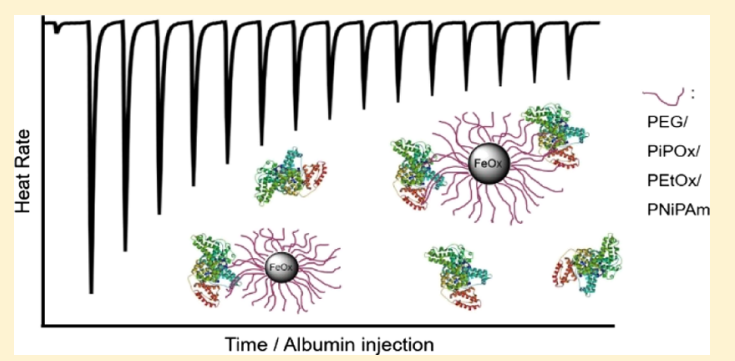
brush shells that "stealth" core-shell nanoparticles display significant attractive exothermic and enthalpic interactions with serum proteins, despite having excellent colloidal stability and negligible nonspecific cell uptake. This observation is at room temperature shown to depend only weakly on variation of iron oxide core diameter and type of grafted stealth polymer: poly(ethylene glycol), poly(ethyl oxazoline), poly(isopropyl oxazoline), and poly( $N$-isopropyl acrylamide). Polymer brush shells with a critical solution temperature close to body temperature showed a strong temperature dependence in their interactions with proteins with a significant increase in protein binding energy with increased temperature. The stoichiometry of interaction is estimated to be near 1:1 for PEGylated nanoparticles and up to 10:1 for larger thermoresponsive nanoparticles, whereas the average free energy of interaction is enthalpically driven and comparable to a weak hydrogen bond.
\end{abstract}

\section{INTRODUCTION}

Core-shell nanoparticles receive ever increasing attention for their current and potential applications in life sciences. ${ }^{1,2}$ Independent tailoring of the core and the shell is used to optimize particles to the many divergent functional demands on biomedical and biotechnological nanoparticles. ${ }^{3,4}$ The core can provide functions such as imaging contrast, controlled drug storage and release as well as novel therapeutic functions. ${ }^{5} \mathrm{~A}$ common strategy is to encapsulate the core in a polymer shell to avoid recognition, degradation, and loss of function in a biological environment because of aggregation and clearance. ${ }^{2,3}$ A dense but well-hydrated polymer shell introduces a stericosmotic repulsive interface that can counteract attractive nonspecific colloidal [Derjaguin-Landau-Verwey-Overbeek (DLVO)] interactions and thereby suppress protein adsorption, nonspecific cell uptake, and clearance in vivo., ${ }^{3,6}$ State of the art for polymer coatings of monodisperse nanoparticles are grafted polymer brushes, for which poly(ethylene glycol) (PEG) is by far the most common in applications and also the most investigated. Although a seemingly successful strategy, the extent to which PEG brushes stabilize core-shell nanoparticles is not clear; ${ }^{7}$ the requirements on polymer grafting density and molecular weight with respect to particle size and the extent of reduction in protein interaction are still open topics, although the consensus is that achieving a very high and completely sterically blocking polymer concentration close to the core is required to benefit from brush repulsion. ${ }^{8}$

The low stability of PEG in biological environments and the increasing production of antibodies against PEG have led to the search for alternatives with similar properties (uncharged, hydrophilic, and flexible) but with better long-term performance, lower cost, and higher versatility than PEG. ${ }^{9}$ Alternatives that are thermoresponsive, such as poly(oxazolines) and poly( $\mathrm{N}$-isopropyl acrylamid) (PNiPAm), are particularly interesting because of their ability to turn core-shell nanoparticles into responsive "smart" materials that can change or modify their function through local or environmental stimuli. ${ }^{10}$ However, although investigated as alternatives for years, even less is known about the interactions of these polymers grafted to particles designed for biomedical applications. It is typically assumed that the results obtained for PEG brushes regarding protein and cell interactions can be extrapolated to these similar polymer brushes.

Thus, despite the speed of development including abundant endpoint cell uptake and in vivo testing of nanoparticles, ${ }^{11}$ relatively little is known about their interactions with other

Received: $\quad$ March 9, 2018

Revised: April 24, 2018

Published: May 4, 2018 
objects in biological fluids. Proteins in blood and serum generally are known to bind to unfunctionalized nanoparticles to form a corona; the amount and presentation of proteins in this corona control the in vivo uptake and clearance irrespective of the original particle properties. ${ }^{12}$ Polymer functionalization of nanoparticles has in many studies been shown to change cell uptake and in vivo clearance; ${ }^{13-15}$ for example, PEG brushes have resulted in so low levels of uptake and clearance that such coatings have been called "stealth" ${ }^{14}$ However, the mechanism for this improvement of suppression of the formation of a protein corona has mainly been extrapolated from investigations of the protein resistance of polymer brushes on planar surfaces; in recent years, this view has been questioned for nanoparticles, suggesting that specific protein interaction with polymer-modified particles is responsible, or even required, for the stealth effect to be observed. ${ }^{16,17}$ Knowledge of affinities and stoichiometries of serum protein in association with polymer functionalized and in particular with polymer brushgrafted nanoparticles is therefore of highest importance for understanding and improving the design of nanoparticles for use in vivo.

Superparamagnetic iron oxide core-shell nanoparticles (SPION) are nanoparticles of particular interest for biomedical and biotechnological applications ${ }^{18,19}$ because of their biocompatibility, low toxicity, and unique magnetic properties. $^{20-22}$ Additionally, recent advances in synthesis of highly monodisperse iron oxide cores ${ }^{23}$ as well as in grafting of polymer brushes and functionalization ${ }^{24,25}$ of such tailored cores make them highly suitable as a platform to quantitatively investigate the effect of shell architecture on interactions with biomolecules and cells. We have recently shown that tailoring of densely and irreversibly grafted PEG and poly(oxazoline) brush shells of different morphologies on monodisperse SPION can lead to phenomenal colloidal stability in serum and in media containing proteins, ${ }^{26-28}$ suppression of interactions with lipid membranes, and the possibility to suppress and control cell uptake. ${ }^{29,30}$ Despite the demonstrations of remarkable and desired so-called stealth colloidal properties, none of these studies have directly measured thermodynamic parameters for the interaction with serum proteins. Being able to avoid adsorption of proteins from blood plasma, for which serum and albumin dispersions are simpler models, is believed to be the crucial first step of suppressing clearance by phagocytic cells and other filtration mechanisms.

Isothermal titration calorimetry (ITC) is a highly sensitive method to study interactions in solution. ${ }^{31-34}$ It can be employed to quickly and accurately characterize both low and high affinity interactions in real time, without introduction of labels. It does so not only by directly providing the Gibbs free energy of the interaction, but also under suitable experimental conditions, the enthalpy, entropy, and stoichiometry of the interaction. Recent advances in instrumentation and processing of ITC data have further increased the attractiveness of using ITC to study interactions of nanomaterials with biological molecules.

In this work, we use a library of core-shell nanoparticles with various suggested stealth polymers irreversibly grafted at high (spherical brush) densities to monodisperse SPION cores using stable nitrodopamide anchors. We also vary the size of the SPION core of PEG-grafted nanoparticles to investigate the effect of changing the strength of the van der Waals (vdW) attraction of the core and the strong effect of surface curvature on the polymer shell brush morphology. The interaction of these SPION with pure albumin and with fetal bovine serum (FBS) was investigated using ITC. Albumin is the most abundant protein in blood, and even though it is thought to have only a weak interaction with stealth core-shell nanoparticles, its pure abundance will ensure association of albumins on the nanoparticle surface even for a weak net attractive protein-nanoparticle interaction.

\section{MATERIALS AND METHODS}

Materials. The standard protein ladder for electrophoresis, prestained PageRuler Plus, was purchased from PEQLAB. Precast TGX gels were purchased from Bio-Rad. Tris(hydroxymethyl)aminomethane (Tris), glycin, sodium dodecyl sulfate (SDS), $\beta$-mercaptoethanol, and glycerol were purchased from Sigma-Aldrich in electrophoresis quality, and Coomassie brilliant blue $G$ tablets were purchased from Gerbu. 4-(2Hydroxyethyl)-1-piperazineethanesulfonic acid (HEPES), $\mathrm{NaCl}, \mathrm{KCl}$, and bovine serum albumin (BSA) were also purchased from Sigma-Aldrich. Regenerated cellulose (RC) $0.22 \mu \mathrm{m}$ filter units were purchased from Bruckner Analysentechnik. Methyl $p$-tosylate was purified by distillation. (1Cyano-2-ethoxy-2-oxoethylidenaminooxy) dimethylamino-morpholino carbenium hexafluorophosphate (COMU) >99\%, dialysis tubes [MWCO: $3.5 \mathrm{kDa}(\mathrm{RC})$ and $1000 \mathrm{kDa}$ (cellulose ester, Spectra/Por Float-A-Lyzer)], EtOH (>96\% technical grade), dimethyl formamide (DMF, $>99.9 \%$ ACS reagent), $\mathrm{CHCl}_{3}(\geq 99.5 \%$ containing $100-200 \mathrm{ppm}$ amylenes as a stabilizer), $n$-hexane ( $\geq 95 \%$ chromasolv plus for high-performance liquid chromatography), and petroleum ether $\left(30-50{ }^{\circ} \mathrm{C}\right.$ bp, p.a.) were obtained from Carl Roth. Iron(0) pentacarbonyl (99.99\% trace metal basis), oleic acid ( $\geq 93 \%$ technical grade), dioctyl ether $(>99 \%)$, dopamine hydrochloride $(\geq 98 \%)$, sulfuric acid (95-98\%), sodium nitrite ( $\geq 99 \%)$, 4-methylmorpholine (99\% ReagentPlus), hydrochloric acid (37\% ACS reagent), and methoxy-PEG acetic acid (MeO-PEG-COOH, $M_{\mathrm{w}}$ : 5000) were obtained from JenKem Technology.

Synthesis of SPION. The synthesis of oleic acid-coated SPION followed established protocols. ${ }^{23,24}$ Briefly, iron oxide nanoparticles were synthesized by thermal decomposition of iron $(0)$ pentacarbonyl in dioctyl ether in the presence of oleic acid, leading to highly monodisperse, spherical, single-crystal iron oxide nanoparticles. The molar ratio between iron(0) pentacarbonyl and oleic acid determines the size of the resulting particles. By increasing the amount of oleic acid, the size of the nanoparticles will also increase. ${ }^{23,35}$

Polymerization of Oxazoline. Poly(2-ethyl-2-oxazoline), poly(2-isopropyl-2-oxazoline), and poly(2-isopropyl-2-oxazoline-co-2-ethyl-2-oxazoline) were polymerized in an analogue fashion. As an example, $2.7 \mathrm{~mL}(23 \mathrm{mmol})$ of 2-isopropyl-2oxazoline was dissolved in $8 \mathrm{~mL}$ of dimethyl acetamide under inert atmosphere. To the reaction solution, $25 \mu \mathrm{L}(0.16 \mathrm{mmol})$ of methyl $p$-tosylate was added. The reaction was stirred for 16 $\mathrm{h}$ at $100{ }^{\circ} \mathrm{C}$; afterward, the reaction was quenched with $200 \mu \mathrm{L}$ of water at $70{ }^{\circ} \mathrm{C}$ for another $5 \mathrm{~h}$. Quenching with water introduces a terminal $\mathrm{OH}$ group. The final product was precipitated with a 1:1 (v/v) mixture of diethyl ether and hexane. It was dried under vacuum. A quantitative yield of $2.7 \mathrm{~g}$ was obtained. The molecular weight was determined with gel permeation chromatography (GPC) and was $19042 \mathrm{~g} / \mathrm{mol}$ with a polydispersity index (PDI) of 1.09. Poly(2-ethyl-2oxazoline) $\left(M_{\mathrm{n}}: 20315 \mathrm{~g} / \mathrm{mol}, \mathrm{PDI}: 1.07\right.$ and $M_{\mathrm{n}}: 22900 \mathrm{~g} /$ mol, PDI: 1.12) and the copolymer of 2-isopropyl-2-oxazoline 
and 2-ethyl-2-oxazoline $\left(M_{\mathrm{n}}: 18285 \mathrm{~g} / \mathrm{mol}, \mathrm{PDI} 1.07\right)$ were prepared in the same way.

Functionalization of Poly(oxazoline). As a representative sample for all poly(oxazoline), the functionalization of poly(2isopropyl-2-oxazoline) is described. Hydroxy-terminated poly(2-isopropyl-2-oxazoline) ( $2.7 \mathrm{~g}, 0.14 \mathrm{mmol})$ was dissolved in $20 \mathrm{~mL}$ of dry chloroform. To the reaction mixture, $216.0 \mathrm{mg}$ $(2.2 \mathrm{mmol})$ of succinic anhydride and $82.2 \mathrm{mg}(0.7 \mathrm{mmol})$ of 4-(dimethylamino) pyridine (DMAP) were added. The reaction was refluxed for $24 \mathrm{~h}$. The carboxylic acid-terminated product was precipitated with a mixture of diethyl ether and hexane $(1 / 1: \mathrm{v} / \mathrm{v})$. Yield: $1.76 \mathrm{~g}$ (65\%). 6-Nitrodopamine (NDA) was chosen to anchor all polymers to the nanoparticle surface because it has a strong binding of covalent character to $\mathrm{Fe}(\mathrm{III}){ }^{25,36}$ Amid coupling of NDA to the carboxylic acidterminated polymer was carried out. Therefore, $1.7 \mathrm{mg}(0.09$ $\mathrm{mmol}$ ) of carboxylic acid-terminated poly(2-isopropyl-2-oxazoline) was dissolved in $20 \mathrm{~mL}$ of dry DMF under inert atmosphere. Subsequently, COMU (223.6 mg, $0.5 \mathrm{mmol})$ and diisopropyl ethylamine (DiPEA) $(0.3 \mathrm{~mL}, 1.7 \mathrm{mmol})$ were added. The carboxylic acid was activated for $10 \mathrm{~min}$, after then NDA (189.2 mg, $0.64 \mathrm{mmol})$ was added. The reaction mixture was stirred for $24 \mathrm{~h}$. The product was precipitated from diethyl ether and hexane $(1 / 1: \mathrm{v} / \mathrm{v})$ and dialyzed for 3 days with a cutoff of $3.5 \mathrm{kDa}$. Yield: $1.4 \mathrm{~g}$, 52\%; functionalization: $97 \%$.

NMR: ${ }^{1} \mathrm{H}$ NMR for poly(2-isopropyl-2-oxazoline)-NDA $\delta \mathrm{H}$ $\left(300 \mathrm{MHz} ; \mathrm{CDCl}_{3}\right) 7.61$ (1H, s, Ar-H), $6.65(1 \mathrm{H}, \mathrm{s}, \mathrm{Ar}-\mathrm{H})$, $4.18\left(2 \mathrm{H}, \mathrm{CH}_{2} \mathrm{OCO}-\right)$, $3.45\left(4 \mathrm{nH},-\mathrm{N}-\mathrm{CH}_{2} \mathrm{CH}_{2}-\right.$ polymer $)$, 2.90-2.61 (1nH, $\mathrm{CH}\left(\mathrm{CH}_{3}\right)_{2}$, polymer), 1.09 (6nH, CH$\left(\mathrm{CH}_{3}\right)_{2}$, polymer).

Polymerization of PNiPAm. $\mathrm{N}$-isopropylacrylamide ( $2 \mathrm{~g}$, $17.7 \mathrm{mmol}$ ) was dissolved in $20 \mathrm{~mL}$ of a mixture of water and methanol (v/v: 9/1). Subsequently, $25.7 \mathrm{mg}(0.18 \mathrm{mmol})$ of $\mathrm{CuBr}, 4.0 \mathrm{mg}(0.02 \mathrm{mmol})$ of $\mathrm{CuBr}_{2}$, and $16.2 \mathrm{mg}(0.10 \mathrm{mmol})$ of 2-bromo-2-methylpropionic acid were added to the solution. The reaction mixture was degassed with $\mathrm{N}_{2}$ for $15 \mathrm{~min}$. Tris[2(dimethylamino)ethyl]amine (Me6Tren, $80 \mu \mathrm{L}, 0.30 \mathrm{mmol}$ ) was dissolved in $1 \mathrm{~mL}$ of water and degassed with $\mathrm{N}_{2}$. Both solutions were cooled to $4{ }^{\circ} \mathrm{C}$ and mixed. The reaction mixture was stirred for $24 \mathrm{~h}$. The product was precipitated thermally and dialyzed $24 \mathrm{~h}$ with a cutoff of $3.5 \mathrm{kDa}$. Yield: $1.5 \mathrm{~g}$, 75\%. The molecular weight was determined by GPC: $17951 \mathrm{~g} / \mathrm{mol}$, PDI: 1.91.

Functionalization of Poly( $\mathrm{N}$-isopropyl acrylaminde). Carboxylic acid-terminated PNiPAm (1.5 g, $0.08 \mathrm{mmol})$ was dissolved in $20 \mathrm{~mL}$ of dry DMF. Subsequently, COMU (119.1 $\mathrm{mg}, 0.28 \mathrm{mmol})$ and DiPEA $(140 \mu \mathrm{L}, 0.80 \mathrm{mmol})$ were added. The reaction mixture was stirred for $15 \mathrm{~min}$. NDA ( $99 \mathrm{mg}, 0.33$ mmol) was added and stirred for another $24 \mathrm{~h}$. The product was precipitated with diethyl ether and hexane $(1 / 1: \mathrm{v} / \mathrm{v})$ and dialyzed for 3 days with a cutoff of $3.5 \mathrm{kDa}$. Yield: $1.3 \mathrm{~g}(65 \%)$ and functionalization: $70 \%$.

NMR: $1 \mathrm{H}$ NMR (300 MHz, $\left.\mathrm{CD}_{3} \mathrm{OD}, \delta\right): 7.58(\mathrm{~s}, 1 \mathrm{H}), 6.70$ (s, $1 \mathrm{H}), 3.98(\mathrm{~s}, 1 \mathrm{nH}$, polymer), $3.49(\mathrm{~m}, 2 \mathrm{H}), 3.05(\mathrm{t}, 2 \mathrm{H})$, 1.18-2.10 (m, 9nH, polymer).

Polymer Characterization. ${ }^{1} \mathrm{H}$ NMR spectra of polymers were measured on a Bruker AV III $300 \mathrm{MHz}$ spectrometer. Chemical shifts were recorded in parts per million (ppm) and referenced to a residual protonated solvent $\left[\mathrm{CDCl}_{3}: 7.27 \mathrm{ppm}\right.$ $(1 \mathrm{H})$ and MeOD: $3.31(1 \mathrm{H})]$. Polymer MWs were measured by GPC on a Malvern Viscotek GPCmax system. The setup comprises three MZ-Gel SDplus columns (a precolumn followed by two columns with separation ranges of 10-2000
$\mathrm{kDa}$ and 1-40 kDa, respectively). A Knauer Smartline RI detector 2300 was used to detect the difference in refractive index. DMF with $0.05 \mathrm{LiBr}$ was applied as an eluent. Samples $(50 \mu \mathrm{L})$ with a concentration of $3 \mathrm{~g} / \mathrm{L}$ were injected and measured at $60{ }^{\circ} \mathrm{C}$ at a flow rate of $0.5 \mathrm{~mL} / \mathrm{min}$. OminSEC 5.12 was used for analysis. Polystyrene standards of 1.5-651 $\mathrm{kg} / \mathrm{mol}$ were used for external calibration.

Grafting of NDA-Functionalized Polymer to SPION. As a representative sample, the reaction of poly(2-isopropyl-2oxazoline) terminated with NDA is described in detail. Wet iron oxide nanoparticles (with an inorganic fraction of $10 \mathrm{wt} \%$ ) were dissolved in $0.5 \mathrm{~mL}$ of toluene. Poly(2-isopropyl-2oxazoline) $(1 \mathrm{~g})$ terminated with NDA was dissolved in $12 \mathrm{~mL}$ of DMF. Both solutions were mixed and sonicated for $24 \mathrm{~h}$. The product was precipitated with diethyl ether and hexane (1/ $1: \mathrm{v} / \mathrm{v}$ ) and dialyzed for 3 days with a cutoff of $100 \mathrm{kDa}$ to remove all excess dispersant. The PNiPAm particles were instead purified by fractional precipitation as described previously. ${ }^{24}$ Shortly, the sample was dissolved in $10 \mathrm{~mL}$ of THF and precipitated by adding stepwise $1 \mathrm{~mL}$ portions of diethyl ether until the particles were possible to decant using a $1 \mathrm{~T}$ permanent magnet. This step was repeated five times until all free dispersants were removed.

Grafting of PEG(5 kDa) to SPION. To ensure stably grafted PEG shells, PEG( $5 \mathrm{kDa})$ was anchored to the surface of the iron oxide nanoparticles by nitrodopamine, ${ }^{25}$ following a ligand replacement procedure described in Lassenberger et al. ${ }^{24}$ NDA-hemisulfate (NDA- $\mathrm{HSO}_{4}$ ) was synthesized according to the literature with slight modifications. ${ }^{37} \operatorname{NDA}-\operatorname{PEG}(5 \mathrm{kDa})$ was synthesized by COMU-mediated peptide-coupling reactions (see the Supporting Information for experimental details). ${ }^{38,39}$ Ligand replacement took place in 10-fold excess (with respect to the expected grafting density, e.g., $3.0 \mathrm{~g}$ of NDA-PEG $(5 \mathrm{kDa})$ for $3.3 \mathrm{~nm} \mathrm{NPs}, 2.0 \mathrm{~g}$ for $6.7 \mathrm{~nm} \mathrm{NPs}$, and $1.8 \mathrm{~g}$ for $8.0 \mathrm{~nm} \mathrm{NPs})$. NDA-PEG $(5 \mathrm{kDa})$ was dissolved in DMF and mixed with $1.2 \mathrm{~g}$ of the respective OA-SPION. Typically, $1.2 \mathrm{~g}$ of iron oxide nanoparticles was dispersed in 30 $\mathrm{mL}$ of DMF and the desired amount of NDA-PEG $(5 \mathrm{kDa})$. The dispersion was sonicated for $26 \mathrm{~h}$ at slightly elevated temperature $\left(35^{\circ} \mathrm{C}\right)$. Subsequently, the mixture was extracted thrice with $n$-hexane $(30 \mathrm{~mL}$ each) to remove released oleic acid. Afterward, the solvent was evaporated; the core-shell nanoparticles were lyophilized for $24 \mathrm{~h}$ and purified from excess ligand by magnetic decantation. ${ }^{24}$

Core-Shell SPION Characterization. The grafting density of all particles was determined by thermogravimetric analysis (TGA). Transmission electron micrographs were recorded on FEI Tecnai G2, with $160 \mathrm{kV}$ acceleration voltage on carbon-coated grids. Nanoparticle size distributions were calculated with the freeware Pebbles ${ }^{40}$ based on the analysis of $>1000$ NPs. Thermal gravimetric analysis of the core-shell nanoparticles was performed on a Mettler Toledo TGA/DSC, with $80 \mathrm{~mL} / \mathrm{min}$ synthetic air as a reactive gas, $20 \mathrm{~mL} / \mathrm{min}$ nitrogen as a protective gas, and a heating rate of $10 \mathrm{~K} / \mathrm{min}$ from 25 to $650{ }^{\circ} \mathrm{C}$. The mass loss from 150 to $500{ }^{\circ} \mathrm{C}$ was assigned to the polymer shell, whereas the residual mass was assigned to the inorganic core. The mass loss up to $150{ }^{\circ} \mathrm{C}$ is due to moisture or solvent residues and was corrected for. The grafting density, $\sigma$, was calculated using

$$
\sigma=\frac{\frac{(\% w / w)_{\text {shell }}}{(\% w / w)_{\text {core }}} \rho_{\text {iron oxide }} V_{\text {core }} N_{\mathrm{A}}}{M_{\text {ligand }} A_{\text {core }}}
$$


where $\sigma$ is the grafting density, $(\% w / w)_{\text {shell }}$ is the percentage of mass loss in TGA for the organic fraction corresponding to the ligand shell, $N_{\mathrm{A}}$ is the Avogadro constant, $\rho_{\text {iron oxide }}$ is the density of iron oxide, $V_{\text {core }}$ is the volume, $A_{\text {core }}$ is the area of the iron oxide core calculated from the diameter of the cores measured by TEM, $M_{\text {ligand }}$ is the molecular weight of the ligand, and $(\% w / w)_{\text {core }}$ is the residual mass percentage of the inorganic fraction in TGA. Dynamic light scattering (DLS) measurements [hydrodynamic diameter, critical solution temperature (CST), and temperature cycling experiments] were conducted in Milli-Q water on a Malvern Zetasizer Nano-ZS. The size distribution was calculated using the CONTIN algorithm by the built-in software.

Preparation of Core-Shell SPION Dispersions. HEPESBS buffer $(10 \mathrm{mM})$ was prepared by weighing and dissolving $1.19 \mathrm{~g}$ of HEPES, $4 \mathrm{~g}$ of $\mathrm{NaCl}$, and $0.1 \mathrm{~g}$ of $\mathrm{KCl}$ in $500 \mathrm{~mL}$ of Milli-Q water (final volume), yielding final concentrations of 10 $\mathrm{mM}$ HEPES, $137 \mathrm{mM} \mathrm{NaCl}$, and $2.7 \mathrm{mM} \mathrm{KCl}$. Drops of concentrated $\mathrm{NaOH}$ were added to reach a final $\mathrm{pH}$ of 7.4. The buffer was filtered after preparation and stored at $4{ }^{\circ} \mathrm{C}$. SPION were weighted using a Sartorius Secura Micro Balance and then dissolved at the desired concentration in HEPES-BS. PEGylated SPION were left to dissolve overnight; poly(oxazoline)-coated particles were used immediately. Each sample was sonicated for a few seconds using a Transsonic $\mathrm{T}$ 460 bath sonicator in order to break up any remaining aggregates. After sonication, each sample was filtered using 0.22 $\mu \mathrm{m}$ RC filter units.

Isothermal Titration Calorimetry. ITC measurements were performed using MicroCal Auto-iTC200 at $25^{\circ} \mathrm{C}$. In each measurement, a sample of $35 \mathrm{mg} / \mathrm{mL}$ BSA in HEPES-BS acted as the titrant and $40 \mu \mathrm{L}$ were filled in the syringe. The cell was filled with the SPION dispersion. A PEGylated $3.3 \mathrm{~nm}$ core was measured at $3 \mathrm{mg} / \mathrm{mL}$, corresponding to $16.5 \mu \mathrm{M}$ particles, and 6.7 and $8.0 \mathrm{~nm}$ at 3.75 and $6.15 \mathrm{mg} / \mathrm{mL}$ respectively, which both correspond to $4.1 \mu \mathrm{M}$ particles. PiPOx, PEtOx (0.4 chains $\left./ \mathrm{nm}^{2}\right)$, PEtOx (0.7 chains $\left./ \mathrm{nm}^{2}\right)$, PiPOx-co-PEtOx, and PNiPAm were all measured at $5 \mathrm{mg} / \mathrm{mL}$ particles, which corresponds to $1.3,2.0,1.1,1.3$, and $1.0 \mu \mathrm{M}$ particles, respectively. The free polymer concentrations were chosen to correspond to the polymer concentrations in the nanoparticle samples according to the organic fraction measured by TGA, i.e., PiPOx $4 \mathrm{mg} / \mathrm{mL}$, PEtOx $3.32 \mathrm{mg} / \mathrm{mL}$, PiPOx-co-PEtOx 4 $\mathrm{mg} / \mathrm{mL}$, PNiPAm $4.2 \mathrm{mg} / \mathrm{mL}$, and PEG $2.5 \mathrm{mg} / \mathrm{mL}$. PiPOx, PEtOx, and the copolymer have one methyl and one hydroxy terminal group; PNiPAm has one carboxy and one hydroxy terminal group; PEG has methoxy-terminal groups. Resovist was measured at $2.5 \mathrm{mg} / \mathrm{mL}$. Each sample was freshly dissolved, filtered and degassed, and used on the same day. During the measurement, $2.5 \mu \mathrm{L}$ of titrant was added every 3 min to the measuring cell for a total of 15 injections. The first injection of $0.5 \mu \mathrm{L}$ is customarily removed from the analysis to avoid artifacts. The data processing was done using the MicroCal PEAQ-ITC analysis software. We applied the fitting model "single set of identical sites" to best reflect the nature of interaction with a dense and uniform polymer brush shell. Baseline correction was generally done using the fitted offset routine, which estimates and subtracts the heat of dilution from the average of the converging injection enthalpies at the end of the titration curve. For measurements on serum, a direct subtraction of the heats of dilutions of the control sample was instead performed before fitting. A comparison between direct subtraction of the heats of injection and the fitted offset subtraction can be found in the Supporting Information. Although different approaches only yielded minor differences in the fitted thermodynamic parameters, the data quality was much higher for all samples except for serum injection when the fitted offset method was used.

Temperature-dependent ITC experiments were carried out on a Microcal PEAQ-ITC Automated (Malvern Panalytical) and analyzed using the MicroCal PEAQ-ITC analysis software. The concentrations and preparation methods for all samples were as described above, as well as the measurement protocol for injection volume and measurement time. The measurements were done at $15,25,30,35$, and $40{ }^{\circ} \mathrm{C}$ for each sample.

SDS-PAGE Electrophoresis. SDS-polyacrylamide gel electrophoresis (PAGE) was done in a Bio-Rad Mini-PROTEAN Tetra-Cell, using precast TGX-gradient gels $(1 \mathrm{~mm}, 4-20 \% \mathrm{~T}$, 12 well). Running buffer consists of $0.3 \%$ Tris, $1.44 \%$ glycin, and $0.1 \%$ SDS. Sample buffer contains $4 \%$ SDS, $4 \% \quad \beta$ mercaptoethanol, and $40 \%$ glycerol in $125 \mathrm{mM}$ Tris adjusted to pH 6.8 with $\mathrm{HCl}$. For each sample, aliquots of $200 \mu \mathrm{L}$ of SPION (concentration as in ITC) were mixed with $40 \mu \mathrm{L}$ of BSA $(35 \mathrm{mg} / \mathrm{mL}$ in HEPES-BS). After $1 \mathrm{~h}$ incubation, unbound BSA was removed by an Amicon filter unit $(100 \mathrm{kDa})$. Each sample was diluted to a final volume of $1.25 \mathrm{~mL}$ and spun-down at $5000 \mathrm{rpm}$ for $10 \mathrm{~min}$ using an Eppendorf 5804R centrifuge. Dilution and centrifugation were repeated six times in total. After final centrifugation, the sample was diluted with $200 \mu \mathrm{L}$ of HEPES-BS and transferred to an Eppendorf vial. The sample $(16 \mu \mathrm{L})$ was mixed with $4 \mu \mathrm{L}$ of sample buffer and then centrifuged at $13200 \mathrm{rpm}$ for $2 \mathrm{~min}$ in an Eppendorf MiniSpin centrifuge. After centrifugation, the supernatant $(4 \mu \mathrm{L})$ was loaded on top of the gel. Separation was done at a constant voltage $(200 \mathrm{~V}$, max. $30 \mathrm{~mA}$ per gel) for $45 \mathrm{~min}$. Gels were stained with Coomassie brilliant blue G, (Gerbu, 1 tablet in 100 $\mathrm{mL}$ of $40 \% \mathrm{MeOH}, 10 \%$ acetic acid) for $15 \mathrm{~min}$ at $50{ }^{\circ} \mathrm{C}$ and destained with several changes of $10 \%$ acetic acid, until the background was completely clear. Finally, the gel was scanned using a LI-COR Odyssey infrared imager at a wavelength of $800 \mathrm{~nm}$.

\section{RESULTS AND DISCUSSION}

To investigate in detail the interaction of core-shell, so-called "stealth", superparamagnetic iron oxide nanoparticles with proteins relevant for cell interaction studies and that are found in blood, we require well-defined nanoparticles, i.e., monodisperse cores with homogeneous grafted polymer brushes. Core-shell nanoparticles comprising of a monodisperse iron oxide core and a densely and irreversibly grafted polymer shell were synthesized and purified from excess dispersant as described previously ${ }^{24,30}$ and in the Materials and Methods section. Three different core sizes in the superparamagnetic range $(3.3,6.7$, and $8.0 \mathrm{~nm}$ in diameter) were used to investigate the effect of nanoparticle size and shell curvature on the interactions of SPION densely grafted with a PEG spherical brush shell. The effect of polymer shell composition was investigated by synthesizing core-shell SPION with similar core size $(\sim 8 \mathrm{~nm})$, polymer molecular weight $(\sim 20 \mathrm{~kg} / \mathrm{mol})$, and grafting density $\left(\sim 1\right.$ chain $\left./ \mathrm{nm}^{2}\right)$. The PEGylated particles had the same grafting density but a polymer molecular weight of $5 \mathrm{~kg} / \mathrm{mol}$. This reflects the close to one-third lower molecular weight per monomer of PEG than of the other polymers, leading to a similar degree of polymerization for all polymers. Thus, the brush properties of all different polymer shells should be similar, and empirically, 
Table 1. Properties of Iron Oxide Core and Polymer Brush Shell Nanoparticles Used in the Interaction Measurements

\begin{tabular}{|c|c|c|c|c|c|c|}
\hline name & polymer & $\begin{array}{c}M_{\mathrm{n}} \\
{[\mathrm{kg} / \mathrm{mol}]}\end{array}$ & PDI & $\begin{array}{l}\text { core diameter } \\
(\mathrm{nm})\end{array}$ & $\begin{array}{l}\text { grafting density } \\
{\left[\text { chains } / \mathrm{nm}^{2}\right]}\end{array}$ & $\begin{array}{l}\text { hydrodynamic diameter } \\
\text { (DLS) }[\mathrm{nm}]\end{array}$ \\
\hline PEG $3.3 \mathrm{~nm}$ & PEG & 5 & 1.07 & $3.3 \pm 0.4$ & 0.7 & $18.5 \pm 1.8$ \\
\hline PEG $6.7 \mathrm{~nm}$ & PEG & 5 & 1.07 & $6.7 \pm 0.5$ & 0.6 & $17.9 \pm 0.8$ \\
\hline PEG $8.0 \mathrm{~nm}$ & PEG & 5 & 1.07 & $8.0 \pm 00.3$ & 1.0 & $21.4 \pm 1.8$ \\
\hline $\begin{array}{l}\text { PEtOx } \\
\left(0.4 \text { chains } / \mathrm{nm}^{2}\right)\end{array}$ & poly(2-ethyl-2-oxazoline) & 20 & 1.07 & $8.0 \pm 0.4$ & 0.4 & $19.5 \pm 1.4$ \\
\hline $\begin{array}{l}\text { PEtOx } \\
\left(0.7 \text { chains } / \mathrm{nm}^{2}\right)\end{array}$ & poly(2-ethyl-2-oxazoline) & 23 & 1.12 & $8.9 \pm 0.6$ & 0.71 & $27.6 \pm 2.3$ \\
\hline PiPOx-co-PEtOx & $\begin{array}{l}\text { poly(2-isopropyl-2-oxazoline)-st-(2-ethyl-2-oxazoline) } \\
(87: 13)\end{array}$ & 18 & 1.07 & $8.0 \pm 0.4$ & 1.0 & $39.8 \pm 13.5$ \\
\hline PiPOx & poly(2-isopropyl-2-oxazoline) & 19 & 1.09 & $8.0 \pm 0.4$ & 1.1 & $19.9 \pm 1.6$ \\
\hline PNiPAm & poly $(N$-isopropylacrylamide $)$ & 18 & 1.91 & $8.0 \pm 0.4$ & 1.1 & $32.8 \pm 8.3$ \\
\hline
\end{tabular}

they stabilize the nanoparticles equally well. All nanoparticles have been shown to possess excellent colloidal stability in serum and suppressed uptake also by phagocytic cells below the critical solution temperature (CST) of the polymers; polymers with a CST lower than body temperature showed aggregation and high uptake in cell culture performed at $37^{\circ} \mathrm{C}$. ${ }^{30}$ Descriptions of the samples are found in Table 1. Polymer molecular weights of the grafted polymers were determined using calibrated GPC, core diameters were determined by image analysis using Pebbles ${ }^{40}$ of $>1000$ NPs using TEM, and the grafting density was determined using the TGA and TEM data as described in the Materials and Methods section.

ITC is an excellent technique to sensitively measure the thermodynamics of nanoparticle interactions with biomolecules in solution. Other techniques used to determine the fate of nanoparticles in biological environments predominantly rely on estimates of the endpoint, such as colloidal aggregation and precipitation or cell uptake and toxicity. Using such methods, it is not clear whether colloidal stability or "stealth" are direct properties of the polymer brush or if they proceed over interactions with the protein-rich environment. Our previously published data indicate that the PEGylated SPION listed in Table 1 had no interaction with lipid membranes or cells ${ }^{29}$ and that they possess extraordinary colloidal long-term stability in blood serum, even under heat treatment. ${ }^{24}$ This was attributed to the stable, grafted, and sufficiently thick and dense PEG shell that prevents protein adsorption and leads to the absence of specific and nonspecific interactions with cells.

Figure 1 shows an ITC measurement of the interaction of free methoxy-PEG and of 3.3, 6.7, and $8.0 \mathrm{~nm}$ in diameter core SPION densely grafted with NDA-PEG with BSA in HEPESBS. Obviously, despite the colloidal characteristics and previous results obtained for these SPION, there is a significant exothermic interaction between the injected BSA and the nanoparticles. In contrast, there is only a low endothermic peak for injection of BSA to free PEG, which corresponds to the heat of dilution of the injected sample (Figure S1). The differential power used to maintain the reference and sample cells in thermal equilibrium for every injection of BSA is shown in the top row graphs of each panel (i) in Figure 1. Integration of the heating rate for each injection (peak) yields the enthalpies of each injection shown in the bottom row graphs of each panel (ii).

The binding isotherms for the SPION in Figure 1 could be fitted using a model assuming a single set of identical BSA interaction sites on the particles, i.e., assuming a uniform stoichiometry and all binding sites having the same binding energy. For weak nonspecific interactions, a simple model assuming independent binding sites should be suitable. A different model should be chosen if the binding interaction violates the hypothesis that the binding of multiple proteins to a single nanoparticle are independent events with similar interaction energies. An argument for this could be that the protein and nanoparticles have similar size. However, for nonspecific protein binding via DLVO interaction with the core or via extended DLVO interactions with the polymer brush shell, it is unlikely that the binding would be significantly affected by already adsorbed proteins. A disadvantage of assuming a more complex model, for example, with dependent binding sites, is that more parameters must be added to the model, which risks resulting in overdetermined fitting. We therefore conclude that if the simplest and in our view most plausible Langmuir-type interaction model can reproduce the data; then, this model is preferred and should be used.

The fits assuming a single set of identical BSA interaction sites on the particles were obtained by the standard Marquardt method iterating until the $\chi^{2}$ error is minimized; the fits are shown as solid lines in the panels numbered (ii) of Figure 1. The stoichiometry, $n$, of this interaction is roughly found as the molar ratio at the inflection (mid-) point of the enthalpy curve and the dissociation constant $K_{\mathrm{D}}$ from the slope of the curve at this point. Because the enthalpy, $\Delta H$, is directly measured, also the entropy of the interaction, $\Delta S$, can be calculated using the Gibbs equation

$$
\Delta G=R T \ln K_{\mathrm{D}}=\Delta H-T \Delta S
$$

where $\Delta G$ is the Gibbs free energy, $R$ is the gas constant, and $T$ is the experimental temperature. The thermodynamic quantities obtained from fits using the Langmuir/Weisman-type model to the titration data at $25{ }^{\circ} \mathrm{C}$ using $K_{\mathrm{D}}, n$, and $\Delta H$ as free parameters are found in Table 2. As observed in Figure 1 and Table 2, all curves were fitted well using this model but the fits yielded high uncertainties in the thermodynamic parameters that are most sensitive to the titration curve shape. Generally, it is a concern that the Weisman $c$ value, $c=n[\mathrm{M}] / K_{\mathrm{D}}$, where $[\mathrm{M}]$ is the concentration of the receptor or in this case the nanoparticles, should be $c>2^{41}$ because otherwise the shape of the titration curve does not contain the features needed to determine all thermodynamic parameters accurately. The $c$ values of nanoparticle samples are strongly limited by their large size, which leads to higher-order colloidal interactions and high viscosity if the nanoparticle concentration is higher than the low micromolar range, that is, because a high nanoparticle volume fraction is reached already at low molarity. The $c$-values of our samples were therefore limited to $0.01<c<2$, assuming $n=1$ and $0.4<c<2.5$ for values of $n$ from the fits (Table S1). 

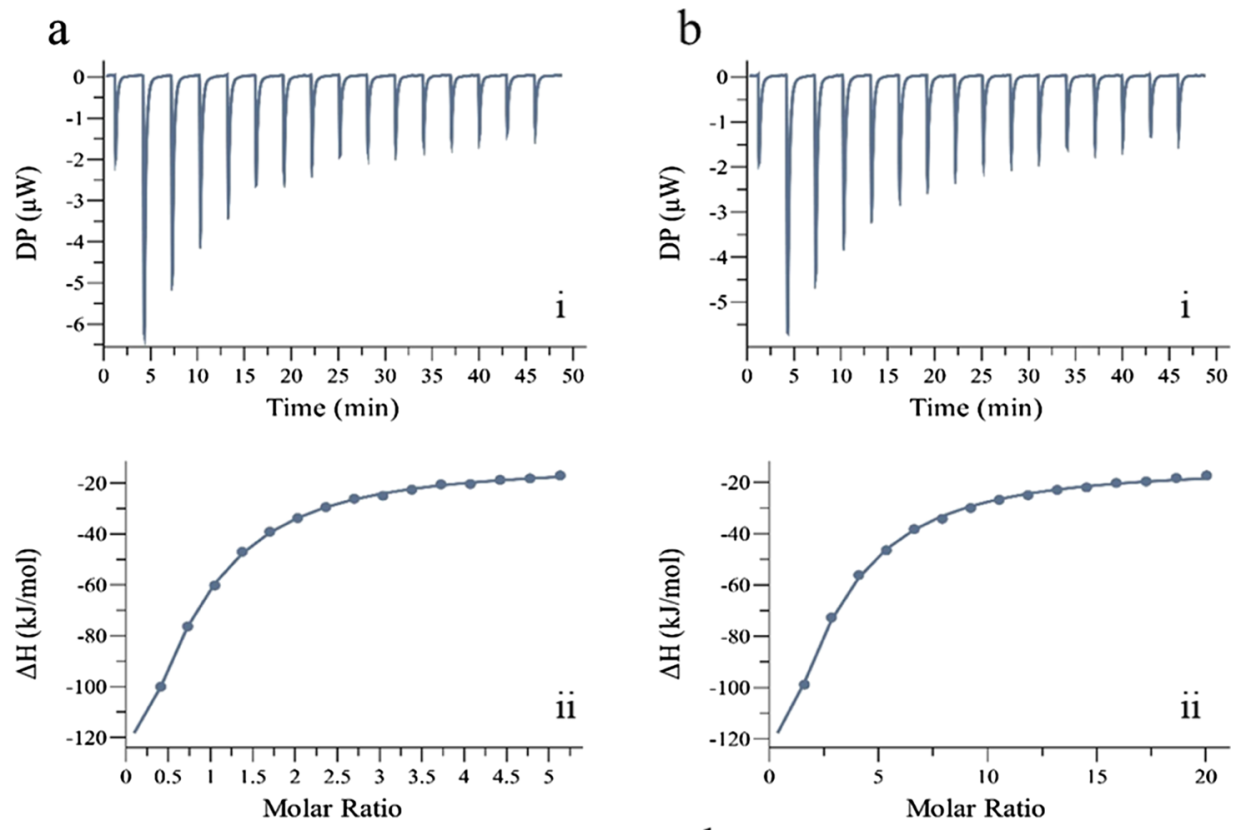

$\mathrm{C}$

$\mathrm{d}$
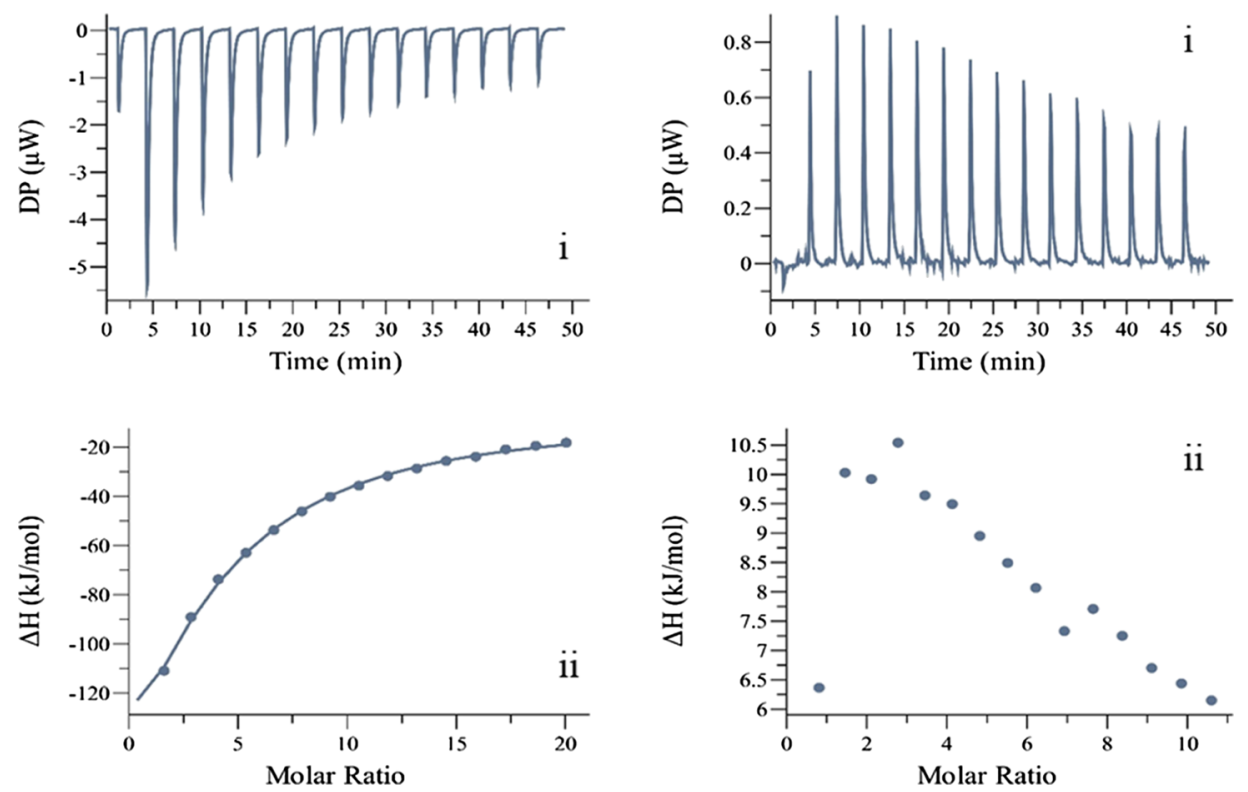

Figure 1. Differential power (heat transfer rate) and enthalpy at $25^{\circ} \mathrm{C}$ upon injection of BSA to SPION grafted with PEG and to free PEG measured by ITC for (a) $35 \mathrm{mg} / \mathrm{mL}$ BSA injected to $3 \mathrm{mg} / \mathrm{mL}(16.5 \mu \mathrm{M}) 3.3 \mathrm{~nm}$ SPION in HEPES-BS, (b) $35 \mathrm{mg} / \mathrm{mL}$ BSA injected to $3.75 \mathrm{mg} / \mathrm{mL}$ (4.1 $\mu \mathrm{M}) 6.7 \mathrm{~nm}$ SPION in HEPES-BS, (c) $35 \mathrm{mg} / \mathrm{mL}$ BSA injected to $6.15 \mathrm{mg} / \mathrm{mL}(4.1 \mu \mathrm{M}) 8.0 \mathrm{~nm}$ SPION in HEPES-BS, and (d) $35 \mathrm{mg} / \mathrm{mL}$ BSA injected to $2.5 \mathrm{mg} / \mathrm{mL}(4.1 \mu \mathrm{M})$ free PEG. Each panel contains the raw heat transfer rate data $(\mathrm{i})$ and calculated interaction enthalpies per injection reflecting the binding isotherms (ii). The continuous lines represent the fitted model.

Table 2. Thermodynamic Parameters for the Interaction between BSA and Nanoparticles Grafted with Polymer Brushes at 25 ${ }^{\circ} \mathrm{C}$ Calculated by Fitting the ITC Data Using a Model Based on a Set of Identical Protein Binding Sites

\begin{tabular}{lccccc}
\multicolumn{1}{c}{ sample } & $n[\mathrm{sites}]$ & $K_{\mathrm{D}}[\mu \mathrm{M}]$ & $\Delta H[\mathrm{~kJ} / \mathrm{mol}]$ & $\Delta G[\mathrm{~kJ} / \mathrm{mol}]$ & $\Delta S[\mathrm{~kJ} / \mathrm{mol} / \mathrm{K}]$ \\
PEG $3.3 \mathrm{~nm}$ & $0.5 \pm 0.06$ & $13.7 \pm 1.4$ & $-291 \pm 44$ & $-27.8 \pm 0.3$ & $-0.88 \pm 0.1$ \\
PEG 6.7 nm & $1.6 \pm 0.4$ & $14.1 \pm 2.4$ & $-335 \pm 110$ & $-27.7 \pm 0.4$ & $-1.03 \pm 0.4$ \\
PEG 8.0 nm & $2.9 \pm 0.6$ & $22.6 \pm 4.8$ & $-335 \pm 102$ & $-26.5 \pm 0.5$ & $-1.03 \pm 0.3$ \\
PEtOx (0.4 chains $/ \mathrm{nm}^{2}$ ) & $10.0 \pm 1.5$ & $16.6 \pm 5.5$ & $-210 \pm 55$ & $-27 \pm 0.8$ & $-0.62 \pm 0.2$ \\
PEtOx (0.7 chains $\left./ \mathrm{nm}^{2}\right)$ & $7.2 \pm 2.5$ & $11.8 \pm 4.7$ & $-340 \pm 160$ & $-28 \pm 1.0$ & $-1.03 \pm 0.5$ \\
PiPOx-co-PEtOx & $7.2 \pm 6.0$ & $18.6 \pm 9.8$ & $-340 \pm 340$ & $-27 \pm 1.3$ & $-1.03 \pm 1.1$ \\
PiPOx & $9.9 \pm 2.1$ & $21.7 \pm 4.5$ & $-340 \pm 97$ & $-27 \pm 0.5$ & $-1.03 \pm 0.3$ \\
PNiPAm & $6.7 \pm 1.5$ & $7.8 \pm 1.5$ & $-340 \pm 90$ & $-29 \pm 0.5$ & $-1.03 \pm 0.3$
\end{tabular}


Recent literature has shown that a robust fit of $K_{\mathrm{D}}$ and thereby $\Delta G$ can be obtained also for $c<10^{-441}$ and that the analysis at very low $c$ is insensitive to errors in $n .^{42}$

ITC is a very sensitive method with many experimental parameters that may cause noise and offsets in the baseline, which in turn influence the fits. The baseline noise was rather high in our measurements, likely through a combination of equipment limitations and that the SPION cannot be dialyzed against the reference media for the very long time periods required to remove all differences in buffer composition. ${ }^{24}$ The colloidally dense medium in the cell and the limitation on dialysis time are also probably causes for why the fitted offset method was better than the direct subtraction of the control sample to remove the heat of injection of the BSA. Thus, although an interaction between BSA and PEG-grafted SPION is indisputable and that the mode of binding seems to agree with the applied model with very robust fits, the enthalpies, entropies, and stoichiometries of interaction are only estimates with quite high uncertainty, whereas a reasonable accuracy is obtained for the dissociation constant and the free energy of interaction.

For very low $c$, the stoichiometry $n$ does not influence the fit as shown by Tellinghuisen ${ }^{41}$ because a low $c$ still yields a good estimate of the tangent of the titration curve at the inflection point from which $K_{\mathrm{D}}$ is obtained, but the titration data then contain little additional shape information from which to extract $n$. A common approach in the study of specific protein interactions is to determine the stoichiometry by complementary measurements and then fix $n$ in the modeling to reduce the number of free parameters in the fit and improve accuracy. ${ }^{42}$ This works well if $n$ is precisely known or the fit is insensitive to $n$ as for low $c$. For nonspecific interactions, a fixed stoichiometry cannot be expected as there are no defined binding sites. Instead, an average number of proteins are likely to interact attractively with the average particle shell surface. However, for the highest $c$ in our study (corresponding to the PEG-grafted nanoparticles with the smallest core diameter), we obtained fits that have a low uncertainty also in $n$, with $n=0.5$. We therefore also tried fixing $n$ in each fit by scaling $n=0.5$ by the area differences between the nanoparticles according to the DLS hydrodynamic diameters given in Table 1 to reduce the number of fitting parameters. The resulting fits are worse than those with a free $n$, as can be observed by comparing Figure S2 and Figure 1. However, for the PEG-grafted nanoparticles, the values for $n$ scaled in this way do not deviate too far from the average values obtained from the direct fitting of the titration data for each individual particle size. We hence conclude that the Weisman $c$ is not low enough for the fit to be insensitive to $n$ and that the fit of $n$ therefore is both called for and likely to produce a reasonable estimate of the stoichiometry.

When comparing the extracted binding energies and number of binding sites per nanoparticle at $25{ }^{\circ} \mathrm{C}$, it is evident that nanoparticles of different core sizes but grafted with the same density of PEG interact very similarly with BSA. The increase in the core size should substantially increase vdW attraction that promotes protein adsorption and aggregation. However, a constant grafting density of the polymer on the nanoparticles also means that with the rapidly increasing area and lower curvature, the sterically repulsive polymer shell becomes denser and thicker as the particle size increases, despite the lower polymer weight fraction. It should be noted that the polymer brush curvature and therefore segment density profile change significantly for the different particles within this size range.
Although the molar ratio of the BSA-nanoparticle interaction is on the order of $1: 1$, it seems that the smallest cores bind on average fewer BSA and with lower dissociation constant than the larger cores. The difference in binding free energy of BSA to the $3.3 \mathrm{~nm}$ core nanoparticles compared to BSA binding to the larger nanoparticles is small but significant. Following the fits, a lower enthalpy of binding is compensated by a much lower entropic penalty of binding of BSA for the PEG $3.3 \mathrm{~nm}$ particles. One can therefore speculate that a more curved brush is providing less steric penalty to binding although the vdW attraction to the core is also lower. This agrees with the model for steric-osmotic stabilization of nanoparticles with spherical brushes, but with the note that the effects of core attraction and brush repulsion roughly seem to balance with the change in size in this range. However, we should also note that our measurements required very high particle concentrations, at which higher-order virial coefficients might start to play a role in determining changes to the total energy of the system, and that this might have been more pronounced for the PEG 3.3 $\mathrm{nm}$ particles that have the highest concentration. The uncertainties in the fits make it difficult to conclusively discuss the difference in the average number of BSA interacting per particle, but there is a tentative trend toward more protein per nanoparticle as the size increases. As described above, the differences in average $n$ obtained from the fits are required to reproduce the curve shape, which indicates that this trend is more robust than it seems at first glance.

If the interaction of the BSA is with the PEG brush or hindered by it, one would expect the number of protein interactions to roughly scale with the area of the polymer brush shell of the SPION. The hydrodynamic size of the particles was determined by DLS (see Table 1) and shows very similar diameters and therefore surface areas of the different nanoparticles. The small difference in surface area cannot fully explain the difference in the number of BSA binding per SPION, although the number of grafted polymer chains and the size of the core-shell particles increase with the core diameter; the largest particles should according to the DLS results only have $34 \%$ more proteins on the surface, whereas the fits to the titration curves indicate an increase in the average number of bound proteins per particle of almost six times. The hydrodynamic radius could, however, underestimate differences in the effective area of the polymer brush shell, as we expect it to also change conformation with size and curvature at constant grafting density. The data thus support the interpretation that an increase in size or area increases the number of bound proteins, but that the area difference itself cannot fully explain the difference.

Although previous studies on nanoparticle interactions have mainly been performed at a single temperature, it is generally perceived as much more robust to perform protein interaction analysis as a function of temperature. This also enables a traditional van't Hoff analysis of enthalpy and entropy of interaction by plotting $\Delta G$ versus $T$. Figure 2 shows the interaction free energies as a function of temperature for the different nanoparticle samples interacting with BSA. The data in Figure 2 demonstrate that the PEG-grafted nanoparticles are similar, with the two smaller core sizes having almost identical $\Delta G$ over the probed temperature range, whereas the largest PEG-grafted nanoparticles consistently have a marginally lower free energy of interaction.

Within the testable temperature range, $\Delta G$ seems to be reasonably, although not perfectly, linearly related to $T$, as a 


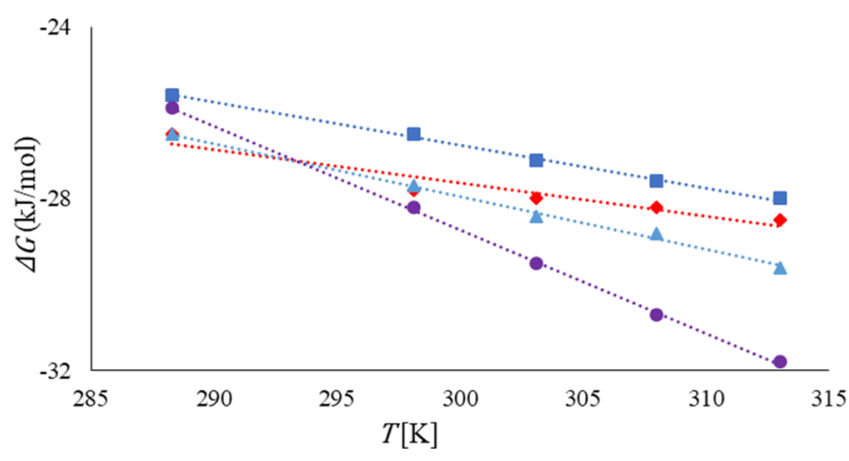

Figure 2. van't Hoff plot of the free energies calculated from the temperature-dependent ITC results for the interaction between BSA and nanoparticles with nonthermoresponsive polymer shells: PEG 3.3 $\mathrm{nm}$ (red diamond), PEG $6.7 \mathrm{~nm}$ (waterblue triangle), PEG $8.0 \mathrm{~nm}$ (turquoise square), and PEtOx (0.7 chains $/ \mathrm{nm}^{2}$ ) (purple round).

simple van't Hoff analysis implies it should be. Table S2 shows $\Delta H$ and $\Delta S$ obtained by the linear regression of the data plotted in Figure 2. The values obtained from this are qualitatively very different from those obtained from fitting the individual titration curves. We observe that the van't Hoff analysis even suggests the opposite signs of the enthalpy and entropy of interaction to what is observed for the fitting of the titration curves. Because the heat of interaction is clearly negative for each injection at a fixed temperature, the difference in the results seems to indicate the limitation of such analysis applied to complex colloidal polymer-protein interactions. The qualitative difference cannot be explained by the standard uncertainty in the analysis from fitting and extrapolating values for $\Delta G$ over a limited temperature range. The probable cause is rather that the enthalpy and entropy of interaction of protein with polymer brush-modified interfaces are not expected to be fully independent of temperature. The hydration of the polymer brush, which is controlled by a competition between water and chain entropy with water hydrogen bonds to the polymer, varies with temperature. As the hydration is decreased with increased temperature, the steric-osmotic repulsive potential preventing protein from adsorbing to the particle is reduced. Close to the CST, this leads to an especially dramatic change from low protein to high protein binding. We therefore probably observe that the temperature dependence of the polymer solvation transition dominates over the proteinparticle interaction in the $T$-dependent response. Interestingly, we observe this even for all of the PEG-grafted nanoparticles, despite the high CST of PEG. We will discuss related results for other polymer brush shells further in a section below.

Although albumin is the most abundant protein in blood serum, other less abundant proteins may have higher affinity to the particle and lead to a permanent protein corona providing specific signals to, e.g., the immune system. To investigate whether other proteins than albumin could dominate the interaction with PEGylated nanoparticles through a stronger interaction, we measured the interaction between SPION with different core sizes grafted with NDA-PEG and 50\% (v/v \%) FBS in HEPES-BS. The raw data and fitted isotherms are reported in Figure S3. The interaction isotherms are close to those for BSA. As expected from the complexity of FBS compared to the BSA solution, this made the isotherms harder to fit with a single-site model mainly because of a worse baseline correction. Additionally, the protein molarity was estimated from the mass assuming an average molecular weight of BSA, which although BSA is by far most abundant protein in FBS could lead to slight errors in the estimated parameters. FBS contains a high but unknown concentration of protein because the protein composition is not precisely known and the interacting proteins can vary. A concentration similar to that used for BSA was chosen, for comparison purposes. The baseline for the FBS measurements is noisy due to heat of dilution of all of the different salts and proteins that FBS contains. Although worse fits were obtained for FBS compared to those for BSA, the obtained thermodynamic parameters for FBS (see Table S3) were very close to those for BSA. We therefore conclude that interactions with BSA dominate any response between serum and nanoparticles grafted with a dense PEG brush and that BSA therefore can be used as a good proxy for measuring average serum protein interactions with PEGgrafted nanoparticles.

There have been recent reports suggesting, in analogy with our results, that albumins indeed interact more strongly with PEG brushes on nanoparticles than previously assumed in the framework of "nonfouling" PEG brushes. The concept of PEG brushes being resistant to protein adsorption is strongly based on the extensive work performed using surface-sensitive techniques on planar PEG brushes; however, the strong colloidal interactions of small nanoparticles and the different structures of highly curved polymer brushes compared to that of planar brushes could lead to higher protein adsorption on PEGylated nanoparticles than that on PEGylated planar surfaces. Parak and co-workers ${ }^{17}$ used fluorescence correlation spectroscopy to show an increase in nanoparticle size of PEGgrafted FePt nanoparticles when exposed to human serum albumin, which was interpreted as adsorption of albumin. A calculation of $K_{\mathrm{D}}$ from the change in hydrodynamic radius at a single temperature when the concentration of protein was changed yielded micromolar dissociation constants that were less than 1 order of magnitude lower than those we measure for the PEG-grafted core-shell SPION by ITC. Their fluorescence lifetime measurements also suggested that the albumin was buried within the PEG shell, which would imply strong adsorption of at least a fraction of the protein on the nanoparticles. Although Parak and co-workers ${ }^{17}$ do not provide a grafting density of the PEG, they describe the thickness of the PEG shell to correspond to that of less densely grafted PEG in the mushroom configuration; this is likely the reason why they observe protein also adsorbing within the PEG shell as the surface of the FePt nanoparticle core is still partly accessible. The adsorption of protein within the brush will have low impact on the hydrodynamic radius; therefore, the adsorption of these strongly adsorbing proteins is not necessarily represented in the determination of $K_{\mathrm{D}}$ by the method chosen in that work. These results are in general agreement with our experiments, but adsorption within the brush and directly to the core suggests that higher affinities should have been observed in these earlier experiments than what we measure. It is also notable that while we observe a stoichiometry of close to $1: 1$, the study on less densely PEG-grafted FePt nanoparticles showed a corona of a full monolayer of albumin forming. However, importantly, these core-shell nanoparticles covered with BSA still demonstrated very low cell uptake. Direct accessibility of the iron oxide core surface to protein adsorption is not likely at the high grafting density, resulting in a spherical PEG brush achieved on our PEG-grafted SPION. Correspondingly, we observe less protein adsorbed per particle, but at 

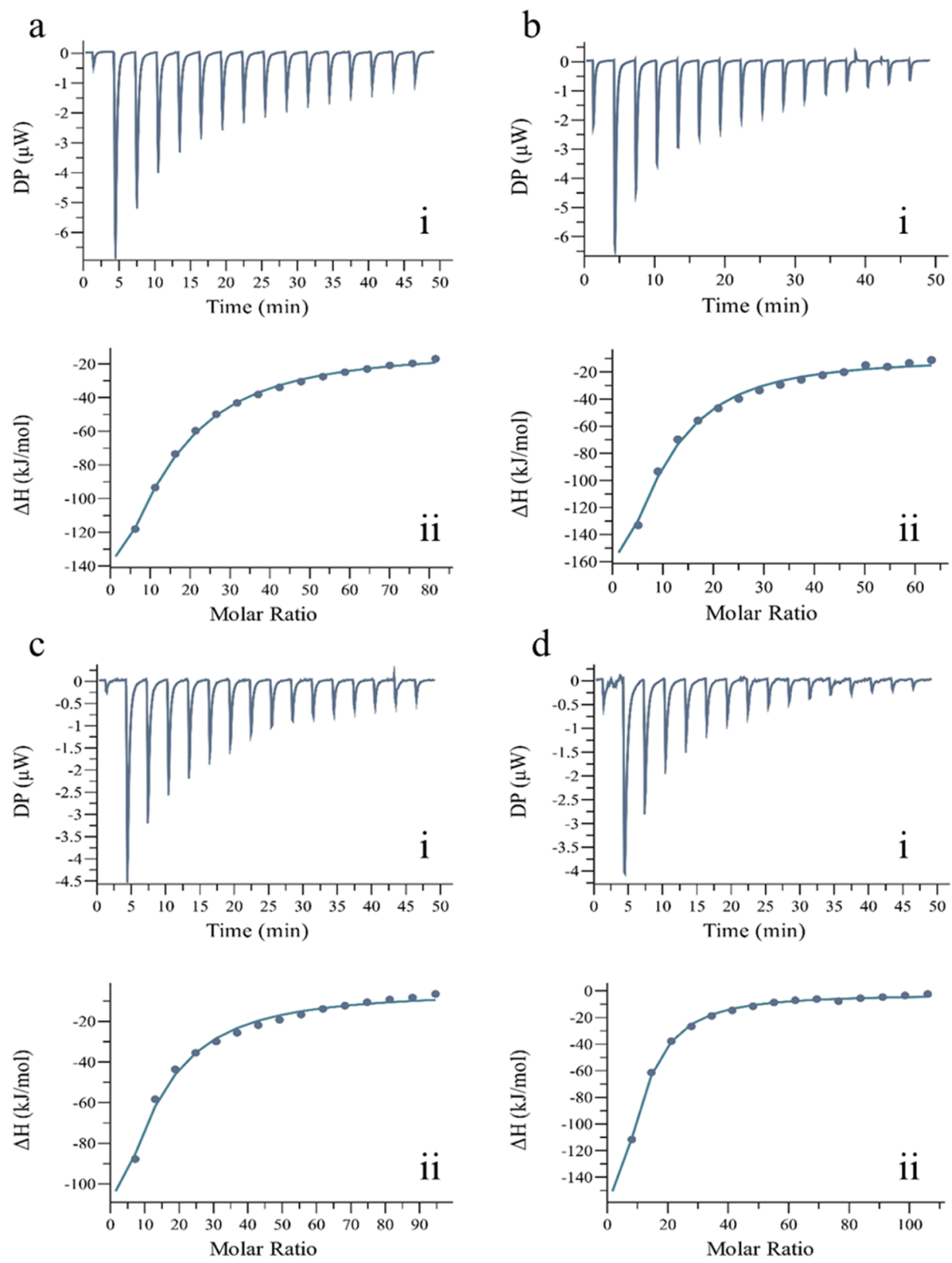

Figure 3. Differential power (heat transfer rate) and enthalpy of interaction at $25{ }^{\circ} \mathrm{C}$ upon injection of BSA to SPION grafted with poly(oxazolines) and PNiPAm measured by ITC for (a) $35 \mathrm{mg} / \mathrm{mL}$ BSA injected to $5 \mathrm{mg} / \mathrm{mL}(1.3 \mu \mathrm{M})$ PiPOx SPION in HEPES-BS, (b) $35 \mathrm{mg} / \mathrm{mL}$ BSA injected to $5 \mathrm{mg} / \mathrm{mL}(1.3 \mu \mathrm{M})$ PEtOx (0.7 chains $\left./ \mathrm{nm}^{2}\right)$ SPION in HEPES-BS, (c) $35 \mathrm{mg} / \mathrm{mL}$ BSA injected to $5 \mathrm{mg} / \mathrm{mL}$ (1.1 $\left.\mu \mathrm{M}\right)$ PiPOx-co-PEtOx SPION in HEPES-BS, and (d) $35 \mathrm{mg} / \mathrm{mL}$ BSA injected to $5 \mathrm{mg} / \mathrm{mL}(1.0 \mu \mathrm{M})$ PNiPAm SPION. Each panel contains the raw heat transfer rate data (i) and calculated interaction enthalpies per injection reflecting the binding isotherms (ii). The continuous lines represent the fitted model.

average higher binding free energy and the same end result, i.e., the particles retain stealth properties in cell uptake experiments.

There are additional reports suggesting that PEG brushes can bind serum proteins and that this can also occur for other substrates than nanoparticles. ${ }^{43,44}$ However, the isotherm in Figure 1d shows that free PEG does not display any interactions with BSA. This raises the question whether our observation of the association of albumin to PEGylated particles is resulting from interactions with PEG or could be a more general feature of polymer brushes, such as the local high density of the polymer, or from the combination of grafted spherical polymer brushes and an inorganic core. Observing the unusual $T$ dependence of the interaction free energy of PEGgrafted nanoparticles also warrants an investigation of if this effect is observed for other temperature-responsive polymer brushes for which the CST can be varied. Therefore, we additionally tested a range of SPION of the same core size (8.0 $\mathrm{nm}$ ) as the largest PEGylated SPION grafted with equally dense brushes of polymers that are regarded as alternatives to PEG to create interfaces resistant to protein adsorption, namely, poly(2-ethyl-2-oxazoline) (PEtOx) and the thermoresponsive polymers poly (2-isopropyl-2-oxazoline) (PiPOx) and poly $(\mathrm{N}$-isopropyl acrylamide) (PNiPAm), as well as a random copolymer of PEtOx and PiPOx (PiPOx-co-PEtOx) with CST close to body temperature. These core-shell nanoparticles have also shown excellent colloidal stability in serum and negligible cell uptake at temperatures below the CST of the shell. ${ }^{30}$ Aggregation and pronounced cell uptake were found for 
Table 3. Thermodynamic Parameters Fitted to the ITC Titration Curves for the Interaction between BSA and PEG 3.3 nm Particles at Different Temperatures

\begin{tabular}{|c|c|c|c|c|c|}
\hline temperature $\left[{ }^{\circ} \mathrm{C}\right]$ & $n[$ sites $]$ & $K_{\mathrm{D}}[\mu \mathrm{M}]$ & $\Delta H[\mathrm{~kJ} / \mathrm{mol}]$ & $\Delta G[\mathrm{~kJ} / \mathrm{mol}]$ & $\Delta S[\mathrm{~kJ} / \mathrm{mol} / \mathrm{K}]$ \\
\hline 15 & $0.5 \pm 0.1$ & $16.3 \pm 2.8$ & $-335 \pm 98$ & $-26.5 \pm 0.4$ & $-1.07 \pm 0.3$ \\
\hline 25 & $0.5 \pm 0.06$ & $13.7 \pm 1.4$ & $-291 \pm 44$ & $-27.8 \pm 0.3$ & $-0.88 \pm 0.1$ \\
\hline 30 & $0.4 \pm 0.07$ & $15.2 \pm 1.6$ & $-335 \pm 72$ & $-28.0 \pm 0.3$ & $-1.01 \pm 0.2$ \\
\hline 35 & $0.4 \pm 0.4$ & $16.6 \pm 8.1$ & $-335 \pm 380$ & $-28.2 \pm 1.2$ & $-1.00 \pm 1.3$ \\
\hline 40 & $0.4 \pm 0.6$ & $17.6 \pm 14$ & $-251 \pm 410$ & $-28.5 \pm 2.0$ & $-0.71 \pm 1.4$ \\
\hline
\end{tabular}

Table 4. Thermodynamic Parameters Fitted to the ITC Titration Curves for the Interaction between BSA and PEG 6.7 nm Particles at Different Temperatures

$\begin{array}{ccc}\text { temperature }\left[{ }^{\circ} \mathrm{C}\right] & n[\text { sites }] & K_{\mathrm{D}}[\mu \mathrm{M}] \\ 15 & 1.9 \pm 0.5 & 15.8 \pm 3.1 \\ 25 & 1.6 \pm 0.4 & 14.1 \pm 2.4 \\ 30 & 1.4 \pm 1.2 & 12.8 \pm 6.0 \\ 35 & 1.2 \pm 1.2 & 13.1 \pm 6.1 \\ 40 & 0.8 \pm 1.5 & 11.8 \pm 7.0\end{array}$

$$
\begin{aligned}
& \Delta H[\mathrm{~kJ} / \mathrm{mol}] \\
& -335 \pm 110 \\
& -335 \pm 110 \\
& -335 \pm 330 \\
& -335 \pm 390 \\
& -335 \pm 670
\end{aligned}
$$

$\Delta G[\mathrm{~kJ} / \mathrm{mol}]$
$-26.5 \pm 0.5$
$-27.7 \pm 0.4$
$-28.4 \pm 1.2$
$-28.8 \pm 1.2$
$-29.6 \pm 1.5$

$$
\begin{gathered}
\Delta S[\mathrm{~kJ} / \mathrm{mol} / \mathrm{K}] \\
-1.07 \pm 0.4 \\
-1.03 \pm 0.4 \\
-1.01 \pm 1.1 \\
-0.99 \pm 1.3 \\
-0.97 \pm 2.3
\end{gathered}
$$

Table 5. Thermodynamic Parameters Fitted to the ITC Titration Curves for the Interaction between BSA and PEG 8.0 nm Particles at Different Temperatures

$\begin{array}{ccc}\text { temperature }\left[{ }^{\circ} \mathrm{C}\right] & n[\text { sites }] & K_{\mathrm{D}}[\mu \mathrm{M}] \\ 15 & 3.2 \pm 0.4 & 23.0 \pm 3.4 \\ 25 & 2.9 \pm 0.6 & 22.6 \pm 4.8 \\ 30 & 2.7 \pm 0.7 & 21.4 \pm 5.5 \\ 35 & 2.2 \pm 1.6 & 21.2 \pm 11.0 \\ 40 & 1.9 \pm 2.5 & 21.5 \pm 16.6\end{array}$

temperatures above the polymer brush CST, which demonstrates that the fully hydrated and steric-osmotically stabilizing polymer brush was responsible for the stealth property. ${ }^{45}$

The ITC curves shown in Figure 3 qualitatively look very similar for all core-shell SPIONs with alternative polymer brush shells at $25^{\circ} \mathrm{C}$, which is below the CST of all polymers. They are very similar also to the PEG-grafted SPION (cf., Figures 1 and 3). Interestingly, in contrast to PEG, most of these polymers show non-negligible interactions with BSA as free polymer coils (Figure S4); only PNiPAm showed very low interaction with BSA, whereas there were exothermic interactions registered for all free poly(oxazoline) coils. The association of BSA is in all cases stronger to the polymergrafted SPION than that to the free polymers. When pondering this comparison, one must also consider that the nanoparticles are much larger than single free polymer coils. Fitting the ITC data with the same model as for the PEG-grafted SPION yielded dissociation constants in the $10 \mu \mathrm{M}$ range with no statistically relevant differences to the PEG-grafted particles with the same core size (Table 2). Very similar enthalpies and entropies of binding were also observed. It should be noted that these other polymers have a higher molecular weight and therefore a slightly denser shell than the PEG-grafted SPION. At a constant grafting density, they therefore have higher organic content and in several cases larger average hydrodynamic size than the PEG-grafted SPION (see Table 1). A higher number of protein, $n$, seemed to bind per particle for the poly(oxazoline)- and PNiPAm-grafted particles, i.e., on average $7-10$ proteins per particle compared to $0.5-3$ proteins per particle on average for PEG-grafted SPION. The particles showing a higher number of associated proteins have larger polymer shells, which would correspond to both a larger area to adsorb to and a larger volume to adsorb into; this could account for most of the observed increase in the protein-to-

$\begin{array}{lcc}\Delta H[\mathrm{~kJ} / \mathrm{mol}] & \Delta G[\mathrm{~kJ} / \mathrm{mol}] & \Delta S[\mathrm{~kJ} / \mathrm{mol} / \mathrm{K}] \\ -335 \pm 66 & -25.6 \pm 2.5 & -1.07 \pm 0.2 \\ -335 \pm 102 & -26.5 \pm 0.5 & -1.03 \pm 0.3 \\ -335 \pm 130 & -27.1 \pm 0.6 & -1.02 \pm 0.4 \\ -335 \pm 308 & -27.6 \pm 1.3 & -1.00 \pm 1.0 \\ -335 \pm 538 & -28.0 \pm 1.9 & -0.98 \pm 1.8\end{array}$

particle binding ratio. Two different samples grafted with PEtOx are also included. These have marginally different core sizes but significantly different grafting densities ( 0.4 vs 0.7 chain $/ \mathrm{nm}^{2}$ ). The significant differences between the two are shown in Table 2 and are noteworthy. Interestingly, both $K_{\mathrm{D}}$ and $n$ seem to be lower at higher grafting density of PEtOx.

The T-dependent data shown in Figure 2 include PEtOxgrafted nanoparticles and show that particles with similar shells have similar van't Hoff plots. As for the PEG-grafted particles, the enthalpy and entropy of interaction obtained by the van't Hoff analysis are significantly different than those obtained from direct fitting of the ITC data. We observe that for the PEtOx-grafted nanoparticles, the difference is even larger with massively positive interaction enthalpy and entropy; both are strongly negative from the analysis of the individual titration curves. We also observe that the interaction free energy is strongly decreasing with increasing temperature. Generally, and compared to PEG-grafted particles, this is to be expected because the hydration of poly(oxazoline) brushes at physiological salt concentration is strongly affected by temperature. The CST is close to the body temperature for PEtOx and below the body temperature for PiPOx at physiological conditions. ${ }^{30,46}$ Consequently, a much stronger $T$ dependence is seen for the BSA binding to PEtOx-grafted than that to PEGgrafted nanoparticles in the investigated temperature range that goes up to $40^{\circ} \mathrm{C}$. A further illustration is that the $T$-responsive polymer shells that have their CST below body temperature cannot be investigated over a sufficiently broad temperature range by ITC or by van't Hoff analysis, that is, PiPOx, PNiPAm, and PiPOx-co-PEtOx samples precipitate with BSA or serum in buffer at temperatures above room temperature and they were therefore excluded from this part of the study. It can also be illustrated by comparing the $T$ dependence of PEtOx-grafted nanoparticles that have different grafting densities shown in 
Table 6. Thermodynamic Parameters Fitted to the ITC Titration Curves for the Interaction between BSA and PEtOx (0.7 Chains $/ \mathrm{nm}^{2}$ ) Particles at Different Temperatures

\begin{tabular}{|c|c|c|c|c|c|}
\hline temperature $\left[{ }^{\circ} \mathrm{C}\right]$ & $n[$ sites $]$ & $K_{\mathrm{D}}[\mu \mathrm{M}]$ & $\Delta H[\mathrm{~kJ} / \mathrm{mol}]$ & $\Delta G[\mathrm{~kJ} / \mathrm{mol}]$ & $\Delta S[\mathrm{~kJ} / \mathrm{mol} / \mathrm{K}]$ \\
\hline 15 & $9.7 \pm 3.4$ & $20.5 \pm 8.4$ & $-335 \pm 177$ & $-26 \pm 1.0$ & $-1.07 \pm 0.6$ \\
\hline 25 & $7.2 \pm 2.5$ & $11.8 \pm 4.7$ & $-335 \pm 161$ & $-28 \pm 1.0$ & $-1.03 \pm 0.5$ \\
\hline 30 & $6.2 \pm 1.8$ & $8.5 \pm 2.8$ & $-335 \pm 126$ & $-30 \pm 0.8$ & $-1.01 \pm 0.4$ \\
\hline 35 & $5.5 \pm 1.0$ & $6.2 \pm 1.4$ & $-335 \pm 80$ & $-31 \pm 0.6$ & $-0.99 \pm 0.3$ \\
\hline 40 & $5.3 \pm 1.4$ & $5.1 \pm 1.8$ & $-335 \pm 116$ & $-32 \pm 0.9$ & $-0.97 \pm 0.4$ \\
\hline
\end{tabular}

Figure S3. A lower grafting density of PEtOx led to lower measurement stability and a dramatic increase in binding free energy at temperatures approaching the CST of the PEtOx brush, whereas a higher grafting density yielded a more stable and constant decrease in interaction free energy with temperature (Figure S3). Clearly, the reduction in density of the strongly repellant brush reduces the ability to withstand protein adsorption, which leads to a more pronounced dependence on temperature as well.

If we investigate the entropy and enthalpy of interaction obtained by fitting the titration curves at different temperatures, we find that they evolve consistently with temperature (see Tables 3-6). In particular, it seems that $\Delta S$ for the BSAnanoparticle interaction observes a quite strong temperature dependence, which again can be rationalized from the $T$ dependent properties of the polymer brush. This is also clearly an effect that is observed more strongly for the PEtOx-grafted nanoparticles and the smallest PEG-grafted nanoparticle than for the larger PEG brush nanoparticles with denser polymer brush shells. The overall $T$ dependence of the nanoparticles with $T$-responsive shells is much stronger than that of the less responsive PEG brush shells, leading to the highest binding energy for the PEtOx-grafted nanoparticles close to body temperature. Finally, from a methodological perspective, we note that a $T$ dependence in $\Delta S$ due to the polymer transition in close to theta solvent conditions favors the ITC analysis of the thermodynamic parameters from the titration curve over a traditional van't Hoff analysis.

For a quantitative analysis, it is important to realize inherent uncertainties when working with nanoparticle dispersions. The measured stoichiometry or average number of binding sites per particle, $n$, relies on that the concentrations of albumin and SPION are correctly known. To calculate the concentration of SPION samples, which are colloidal dispersions, we use the core diameter determined by TEM and the organic fraction determined by TGA to calculate the molarity of particles from the mass of small amounts of particles weighed in by a microbalance. Because of these steps of sample preparation and measurement uncertainties, the calculated molarities could have systematic errors. Additionally, the dispersions of SPION must be filtered before the measurements. There was no noticeable loss of particles during filtration because of their very high colloidal stability, but the filtration adds an additional uncertainty in the molarity used for the calculation. Albumin is known to aggregate over time at high concentration, which after filtration can lead to a reduction of the concentration. Adding up these uncertainties in the molarities used for the thermodynamic calculation means that we should treat the obtained values as order of magnitude estimates, although trends in the data are expected to be conserved from such systematic errors that are similar for the different samples and always work in the same direction.
Finally, the SPION used in our study are designed as excellent contrast agents for magnetic resonance imaging, providing a well-defined and colloidally stable particle platform with high relaxivity and possibility to do cellular targeting. ${ }^{28}$ Clinically used contrast agents have multiple iron oxide nanoparticles enwrapped in a physisorbed shell of dextran, forming multicore, dynamic and hydrodynamically large aggregates. This structure has been shown to lead to low colloidal stability over longer periods of time in serum and to high nonspecific cell uptake compared to, e.g., single-core SPION with irreversibly grafted PEG brushes. ${ }^{28}$ Interestingly, a representative commercial contrast agent, such as Resovist, showed negligible interaction with BSA (Figure S6) and FBS (Figure S3d) measured by ITC, similar to that for free dextran. An ITC experiment, however, measures interactions on the time scale of minutes, whereas the instability of dextran-coated SPION is observed over longer time scales. This demonstrates a limitation of using ITC measurements of protein interactions as a predictor of in vitro and in vivo nanoparticle stability.

All core-shell SPION grafted with a polymer brush had unfavorable entropy for the protein binding in the range 0.5$1.1 \mathrm{~kJ} / \mathrm{mol} / \mathrm{K}$, indicating the penalty of displacing water from the polymer brush and restricting the conformational freedom of the polymer in the brush. The large favorable enthalpy of binding compensates for this and makes the interaction overall favorable. It is notable that the entropic penalty and the enthalpic gain from protein binding are comparable and that the brush thereby seems to play an important role in suppressing protein binding even if the binding might occur to defects within the brush in analogy with the results of Parak and co-workers for nanoparticles grafted with PEG mushrooms mentioned above. The binding energy is on the order of one hydrogen bond and is therefore a significant but quite weak interaction per protein and on the order of $10 k_{\mathrm{B}} T$; this is sufficient to keep nanoparticles and proteins associated if they are not under mechanical, thermal, or other stress.

The indication of strong average association $\left(\sim 10 k_{\mathrm{B}} T\right)$ of albumin to the core-shell SPION made us check whether at least some of the protein is strongly enough adsorbed that it can be found bound to the particles also after separation of excess protein. For this, we incubated the samples for $1 \mathrm{~h}$ at the same concentration and volume used at the end of the ITC measurements and spun down the sample six times using a 100 $\mathrm{kDa}$ Amicon filter. Six cycles were chosen because a sample of BSA without SPION showed complete removal of BSA after this procedure. Residual BSA bound to the particles was dissolved by adding buffer containing SDS, and then the sample was run through one-dimensional (1D) SDS-PAGE. A typical gel with controls is shown in Figure 4, and demonstrates remaining BSA for all incubated core-shell nanoparticles.

There is a lack of similar nanoparticle systems in the literature, i.e., inorganic core nanoparticles with densely grafted polymer brush shells, for which the thermodynamic parameters 


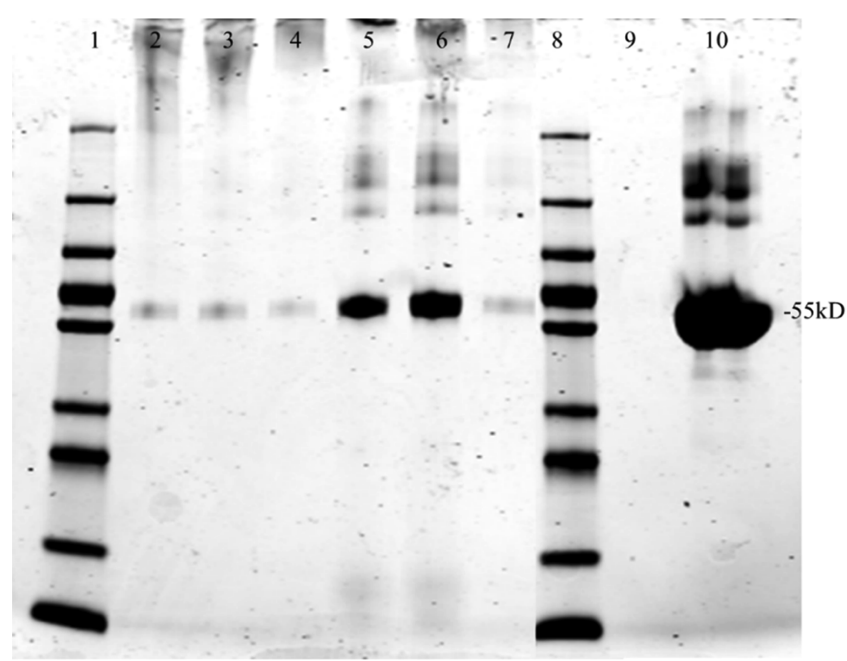

Figure 4. 1D SDS-PAGE of protein dissolved from core-shell SPION samples after incubation with BSA and separation of free BSA in the supernatant. (1,8) Standards; (2-4) PEG-grafted SPION with 3.3, 6.7, and $8.0 \mathrm{~nm}$ cores, respectively; (5) PiPOx; (6) PEtOx (0.4 chains/ $\mathrm{nm}^{2}$ ); (7) PiPOx-co-PEtOx; (9) BSA after six centrifugation cycles; and (10) BSA without centrifugation.

for interactions with proteins have been investigated. The few studies that exist are not investigating the temperature dependence of the protein-nanoparticle interaction. Guo and co-workers ${ }^{47}$ used ITC to measure the interaction between albumin and core-shell nanoparticles comprising a larger (100 $\mathrm{nm})$ PS core grafted with protein-repelling poly $(N$-hydroxyethyl acrylamide) of high molecular weight and with a final average particle hydrodynamic diameter of $\sim 200 \mathrm{~nm}$ measured by DLS. As in the study of Parak et al., it should be noted that the grafting density was low, $\sim 0.1$ chains $/ \mathrm{nm}^{2}$, which even for nanoparticles with low curvature suggests a density lower than that of a brush and lower than that of the low grafting density PEtOx shown here to have a much higher temperature sensitivity than densely grafted PEtOx particles. The low polymer grafting density could thus contribute to both the observed nanoparticle aggregation and the strong protein adsorption. Hence, Guo and co-workers measured a slightly stronger binding of albumin to the particles $(\Delta G=-34 \mathrm{~kJ} /$ mol) and a much higher number of albumin bound per particle $(n \approx 1670),{ }^{47}$ which indicates a substantial permanent protein corona even after considering the size difference. These differences to our observations might be due to a different adsorption mechanism. Guo and co-workers describe the protein adsorption as predominantly entropy driven, whereas in our case, it is purely enthalpy driven.

It is noteworthy that the dissociation constants in the micromolar range that we report are about a factor of 3 higher than what was measured by Linse and co-workers for albumin adsorption to $\mathrm{N}$-isopropylacrylamide-co- $\mathrm{N}$-tert-butylacrylamide (poly(NiPAm-co-BAm $)$ ) copolymer particles without a solid core, for which the hydrophobicity was varied. ${ }^{48,49}$ Contributing to this difference could be a stronger vdW attraction from the SPION core than from a less dense and hydrated polymer particle as well as a possibly higher density of the polymer brush on the SPION. Linse and co-workers also investigated the hydrophobicity/hydrophilicity effect on the BSA adsorption to copolymer nanoparticles with size $70-700 \mathrm{~nm}$. ${ }^{49}$ They made particles from $100 \%$ hydrophilic PNiPAm to $50 \%$ hydrophobic BAm-co-NiPAm copolymer. For all cases, both enthalpy and entropy were within 1 order of magnitude comparable to our results for BSA adsorption to core-shell nanoparticles. For 200 $\mathrm{nm}$ in diameter $100 \%$ PNiPAm particles, the parameters are almost identical for both enthalpy $(-280 \mathrm{~kJ} / \mathrm{mol}$ compared to our $-335 \mathrm{~kJ} / \mathrm{mol})$ and entropy $(-0.88 \mathrm{~kJ} / \mathrm{mol} / \mathrm{K}$ compared to our $-1.03 \mathrm{~kJ} / \mathrm{mol} / \mathrm{K})$, which might indicate a similar adsorption mechanism despite the difference in structure. A much larger amount of protein is bound per particle than that for our core-shell nanoparticles, which is likely mainly due to the much larger area of the polymer particles used by Linse and co-workers. These similarities in the thermodynamic interaction parameters for albumin and dense, essentially hydrogel, polymer particles without core and our particles may suggest that the dense polymer shell also dominates the attractive interaction, and not the underlying core.

Smaller polymer nanoparticles have shown similar affinities. Bhattacharya et al. $^{50}$ measured the interaction of polymer nanodots $(\sim 5 \mathrm{~nm}$ in diameter $)$ with human serum albumin using ITC. Also, in their work, the $K_{\mathrm{D}}(\sim 2 \mu \mathrm{M} ; \Delta G \approx-30 \mathrm{~kJ} /$ $\mathrm{mol}$ ) was close to that of our particles, with a likewise similar stoichiometry of the interaction of 1:1 particles-to-albumin. A major difference, however, was that the interaction was endothermic, which likely was due to the charged end-group termination of the polymer and formation of hydrogen bonds during protein binding.

Our results also seem in line with recent high-profile work, ${ }^{4,16}$ regarding the role of the adsorbed protein corona for the stealth effect of PEGylated nanoparticles. We show that nanoparticles grafted with a polymer brush, regardless of type of nonfouling polymer within the study, exhibit strong association with serum proteins (albumin) while still almost completely suppressing cell uptake. Schöttler et al. even suggested that PEGylated nanoparticles are only "stealth" after adsorption of a corona of proteins. ${ }^{16}$ In particular, adsorption of clusterin was described as necessary to suppress cell uptake of PEGylated nanoparticles. However, it should be noted that the nanoparticles in the study by Schöttler et al. are both 1 order of magnitude larger than ours and have more than 10 times lower grafting density of PEG of less than half the molecular weight; this means that the surface of the core is highly accessible to direct adsorption of protein within the brush and significantly more so than that in the study by Parak and co-workers ${ }^{17}$ discussed above. The number of proteins associated per particle or particle surface area in our study is orders of magnitude lower than in these previous studies, although the $K_{\mathrm{D}}$ of the protein binding is similar. Furthermore, Koshkina et al. compared adsorption of serum proteins on 9 $\mathrm{nm}$ polymer core particles grafted with PEtOx and PEG using size measurements in situ and analysis of adsorbed proteins after separation. ${ }^{51}$ These particles are similar to ours in size and structure but again have an effective polymer grafting density that is ten times lower and thereby do not correspond to a polymer brush. They demonstrated that protein adsorption resulted for all particles in serum with no significant difference between nanoparticles grafted with PEG or PEtOx. The nanoparticles grafted with PEG or PEtOx and with an adsorbed protein corona had much lower cell uptake than particles stabilized by charge, which are also expected to attract strong protein adsorption; in the case of PEtOx-grafted particles, the stability was observed over days.

Our observations regarding proteins associating with polymer brush-functionalized nanoparticles despite suppressed cell uptake (stealth effect) are compatible with all of these 
previous studies, although we observe lower surface coverage of protein and are not likely to have protein strongly bound directly to the particle core surface. What all studies have in common is that the combination of steric stabilization of grafted polymer brushes and a limited, not too strongly adsorbed, amount of protein on the surface of nanoparticles strongly reduces nonspecific recognition and cell uptake. We speculate that the key to this performance is not the total prevention of serum protein adsorption on the nanoparticle surface but the ability of such particles to withstand colloidal aggregation; both the surface-bound polymer and associated proteins that maintain a nativelike configuration contribute a steric spacer to the much stronger attractive colloidal interactions with the particle core. A dense polymer brush can thereby still be advantageous compared to less dense polymer grafts or physisorbed polymers as it both promotes steric stabilization and prevents protein denaturation by maintaining the association with the particle surface weak and uniform.

\section{CONCLUSIONS}

In summary, we have performed the first ITC study of protein interaction with nanoparticles grafted with dense spherical polymer brushes. We have shown that serum proteins, specifically albumin, also adsorb to nanoparticles with cores smaller than $10 \mathrm{~nm}$ and stealth polymers grafted at spherical brush densities. This is observed despite the remarkable high colloidal stability and low cell uptake of these core-shell nanoparticles. Although the number of adsorbed proteins per particle is low, the adsorption energy is high enough to ensure micromolar dissociation constants and near irreversible adsorption of at least some protein for physiological conditions. The binding affinity of albumin was similar over a range of different stealth polymer brushes, but the number of proteins bound per particle seemed slightly lower for PEGylated particles than for particles grafted with poly(oxazoline) or PNiPAm. Measuring the interaction of serum concentrations of BSA was also a good model for the protein interaction of full serum. A strong temperature dependence of the protein interaction with polymer-grafted nanoparticles was observed that correlated with the polymer brush solubility transition temperature. The strong dependence of the system and thereby interaction entropy with temperature invalidated a classical van't Hoff analysis of the interaction enthalpy. On the basis of our results, it is highly unlikely that adsorption of certain proteins is required for low cell uptake of surface-functionalized nanoparticles, as recently reported for large particles with low polymer grafting density. We demonstrate similar results regarding stealth effect with only $\sim 1$ protein associated per nanoparticle with on average of $\sim 10 k_{\mathrm{B}} T$ binding energy. Tentatively, BSA associates with the polymer brush surface in an enthalpically driven binding interaction that depends on direct interaction with the dense polymer brush rather than with the inorganic core. Because less dense polymer grafting tends to lead to particle aggregation as well as strong protein adsorption and opsonization, as also observed here, it is interesting to consider whether the polymer brush density of spherical polymer brushes can at all be optimized to ensure both colloidal stability and no attractive interaction with serum proteins. In the light of our earlier work showing that covalent linking of already a few proteins (avidin) to the polymer brush of such nanoparticles leads to pronounced increase in cell uptake, $^{28}$ it is also interesting for further development of nanoparticles for biomedical use to consider whether it is the properties of adsorbed protein or that they are in a dynamic equilibrium at the surface of the nanoparticles that cause the difference in cell recognition and uptake of differently protein"coated" core-shell nanoparticles.

\section{ASSOCIATED CONTENT}

\section{Supporting Information}

The Supporting Information is available free of charge on the ACS Publications website at DOI: 10.1021/acs.jpcb.8b02338.

ITC curve for BSA and FBS injected to buffer; fits to the heat of injection with $n$ fixed; comparison of $T$ dependence of $\Delta G$ for BSA binding to PEtOx-grafted nanoparticles; FBS injected to PEGylated SPION; BSA injected to free polymer and Resovist; temperaturedependent ITC curves and fits to heat of injection for PEG 3.3 nm, PEG 6.7 nm, PEG $8.0 \mathrm{~nm}$, and PEtOx (0.7 chains $\left./ \mathrm{nm}^{2}\right)$; TEM images of the iron oxide cores; TGA curves for polymer-coated SPION; and attached is the table of $c$-values, a table of enthalpies and entropies from a van't Hoff analysis of the titration data, and a table of thermodynamic parameters for the interaction between FBS and PEGylated SPION (PDF)

\section{AUTHOR INFORMATION}

\section{Corresponding Author}

*E-mail: erik.reimhult@boku.ac.at. Phone: +43-1-47654-80211. Fax: +43-1-47891-12.

\section{ORCID}

Erik Reimhult: 0000-0003-1417-5576

\section{Author Contributions}

N.G. and E.R. planned the work. M.S. synthesized the coreshell SPION. N.G. performed experiments and analyzed the data. N.G. and E.R. wrote the manuscript, which was read and corrected by M.S.

\section{Funding}

The research leading to these results received funding from the European Research Council under the European Union's Seventh Framework Program (FP/2007-2013)/ERC grant agreement no. 310034 and from the Austrian Science Fund (FWF) project P 28190-N28.

\section{Notes}

The authors declare no competing financial interest.

\section{ACKNOWLEDGMENTS}

We thank Dr. Ludwig and the Department of Food Science and Technology (DLWT) for the help and the use of the ITC machine. We thank Andrea Lassenberger and Tanja Zwölfer for contributing the PEGylated SPION and Ronald Zirbs and Andrea Scheberl for providing experimental support and guidance. We thank the EQ-BOKU VIBT GmbH and the BOKU Core Facility for Biomolecular and Cellular Analysis for the use and the technical support for Microcal PEAQ-ITC Automated.

\section{ABBREVIATIONS}

ITC, isothermal titration calorimetry; SPION, superparamagnetic iron oxide nanoparticles; BSA, bovine serum albumin; FBS, fetal bovine serum; HEPES-BS, HEPES buffer saline; PEG, polyethylene glycol; RC filters, regenerated cellulose filters; SDS-PAGE, sodium dodecyl sulfate polyacrylamide gel 
electrophoresis; PNiPAm, poly( $N$-isopropylacrylamide $)$; PiPOx, poly(2-isopropyl-2-oxazoline); PEtOx, poly(2-ethyl-2oxazoline); DAMP, dimethyl amino pyridine; NDA, 6-nitrodopamine; DiPEA, diisopropylethylamine; DMA, dimethylamine; NMR, nuclear magnetic resonance; GPC, gel permeation chromatography; COMU, (1-cyano-2-ethoxy-2oxoethylidenaminooxy) dimethylamino-morpholino carbenium hexafluorophosphate

\section{REFERENCES}

(1) Bobo, D.; Robinson, K. J.; Islam, J.; Thurecht, K. J.; Corrie, S. R. Nanoparticle-Based Medicines: A Review of FDA-Approved Materials and Clinical Trials to Date. Pharm. Res. 2016, 33, 2373-2387.

(2) Niu, M.; Pham-Huy, C.; He, H. Core-Shell Nanoparticles Coated with Molecularly Imprinted Polymers: A Review. Microchim. Acta 2016, 183, 2677-2695.

(3) Verma, A.; Stellacci, F. Effect of Surface Properties on Nanoparticle-Cell Interactions. Small 2010, 6, 12-21.

(4) Feliu, N.; Docter, D.; Heine, M.; del Pino, P.; Ashraf, S.; Kolosnjaj-Tabi, J.; Macchiarini, P.; Nielsen, P.; Alloyeau, D.; Gazeau, F.; et al. In Vivo Degeneration and the Fate of Inorganic Nanoparticles. Chem. Soc. Rev. 2016, 45, 2440-2457.

(5) Zhang, L.; Gu, F. X.; Chan, J. M.; Wang, A. Z.; Langer, R. S.; Farokhzad, O. C. Nanoparticles in Medicine: Therapeutic Applications and Developments. Clin. Pharmacol. Ther. 2008, 83, 761-769.

(6) Kang, B.; Okwieka, P.; Schöttler, S.; Winzen, S.; Langhanki, J.; Mohr, K.; Opatz, T.; Mailänder, V.; Landfester, K.; Wurm, F. R. Carbohydrate-Based Nanocarriers Exhibiting Specific Cell Targeting with Minimum Influence from the Protein Corona. Angew. Chem., Int. Ed. 2015, 54, 7436-7440.

(7) Knop, K.; Hoogenboom, R.; Fischer, D.; Schubert, U. S. Poly(ethylene glycol) in Drug Delivery: Pros and Cons as Well as Potential Alternatives. Angew. Chem., Int. Ed. 2010, 49, 6288-6308.

(8) Mahmoudi, M.; Lynch, I.; Ejtehadi, M. R.; Monopoli, M. P.; Bombelli, F. B.; Laurent, S. Protein-Nanoparticle Interactions: Opportunities and Challenges. Chem. Rev. 2011, 111, 5610-5637.

(9) Qi, Y.; Chilkoti, A. Protein-Polymer Conjugation-Moving Beyond PEGylation. Curr. Opin. Chem. Biol. 2015, 28, 181-193.

(10) Wilson, P.; Ke, P. C.; Davis, T. P.; Kempe, K. Poly(2-oxazoline)Based Micro- and Nanoparticles: A Review. Eur. Polym. J. 2017, 88, 486-515.

(11) Nel, A. E.; Mädler, L.; Velegol, D.; Xia, T.; Hoek, E. M. V.; Somasundaran, P.; Klaessig, F.; Castranova, V.; Thompson, M. Understanding Biophysicochemical Interactions at the Nano-Bio Interface. Nat. Mater. 2009, 8, 543.

(12) Walkey, C. D.; Chan, W. C. W. Understanding and Controlling the Interaction of Nanomaterials with Proteins in a Physiological Environment. Chem. Soc. Rev. 2012, 41, 2780-2799.

(13) Huang, R.; Carney, R. P.; Stellacci, F.; Lau, B. L. T. ProteinNanoparticle Interactions: The Effects of Surface Compositional and Structural Heterogeneity are Scale Dependent. Nanoscale 2013, 5, 6928-6935.

(14) Li, S.-D.; Huang, L. Stealth Nanoparticles: High Density but Sheddable PEG is a Key for Tumor Targeting. J. Controlled Release 2010, 145, 178-181.

(15) Neoh, K. G.; Kang, E. T. Functionalization of Inorganic Nanoparticles with Polymers for Stealth BIomedical Applications. Polym. Chem. 2011, 2, 747-759.

(16) Schöttler, S.; Becker, G.; Winzen, S.; Steinbach, T.; Mohr, K.; Landfester, K.; Mailänder, V.; Wurm, F. R. Protein Adsorption is Required for Stealth Effect of Poly(ethylene glycol)- and Poly(phosphoester)-Coated Nanocarriers. Nat. Nanotechnol. 2016, 11, 372.

(17) Pelaz, B.; del Pino, P.; Maffre, P.; Hartmann, R.; Gallego, M.; Rivera-Fernández, S.; de la Fuente, J. M.; Nienhaus, G. U.; Parak, W. J. Surface Functionalization of Nanoparticles with Polyethylene Glycol: Effects on Protein Adsorption and Cellular Uptake. ACS Nano 2015, 9, 6996-7008.
(18) Amstad, E.; Textor, M.; Reimhult, E. Stabilization and Functionalization of Iron Oxide Nanoparticles for Biomedical Applications. Nanoscale 2011, 3, 2819-2843.

(19) Kim, D. K.; Zhang, Y.; Voit, W.; Rao, K. V.; Kehr, J.; Bjelke, B.; Muhammed, M. Superparamagnetic Iron Oxide Nanoparticles for BioMedical Applications. Scr. Mater. 2001, 44, 1713-1717.

(20) Laurent, S.; Forge, D.; Port, M.; Roch, A.; Robic, C.; Vander Elst, L.; Muller, R. N. Magnetic Iron Oxide Nanoparticles: Synthesis, Stabilization, Vectorization, Physicochemical Characterizations, and Biological Applications. Chem. Rev. 2008, 108, 2064-2110.

(21) Duguet, E.; Vasseur, S.; Mornet, S.; Devoisselle, J.-M. Magnetic Nanoparticles and Their Applications in Medicine. Nanomedicine 2006, 1, 157-168.

(22) Tian, Q.; Hu, J.; Zhu, Y.; Zou, R.; Chen, Z.; Yang, S.; Li, R.; Su, Q.; Han, Y.; Liu, X. Sub-10 nm Fe3O4@Cu2-xS Core-Shell Nanoparticles for Dual-Modal Imaging and Photothermal Therapy. J. Am. Chem. Soc. 2013, 135, 8571-8577.

(23) Hyeon, T.; Lee, S. S.; Park, J.; Chung, Y.; Na, H. B. Synthesis of Highly Crystalline and Monodisperse Maghemite Nanocrystallites without a Size-Selection Process. J. Am. Chem. Soc. 2001, 123, 1279812801.

(24) Lassenberger, A.; Bixner, O.; Gruenewald, T.; Lichtenegger, H.; Zirbs, R.; Reimhult, E. Evaluation of High-Yield Purification Methods on Monodisperse PEG-Grafted Iron Oxide Nanoparticles. Langmuir 2016, 32, 4259-4269.

(25) Amstad, E.; Gillich, T.; Bilecka, I.; Textor, M.; Reimhult, E. Ultrastable Iron Oxide Nanoparticle Colloidal Suspensions Using Dispersants with Catechol-Derived Anchor Groups. Nano Lett. 2009, 9, 4042-4048.

(26) Zirbs, R.; Lassenberger, A.; Vonderhaid, I.; Kurzhals, S.; Reimhult, E. Melt-Grafting for the Synthesis of Core-Shell Nanoparticles with Ultra-High Dispersant Density. Nanoscale 2015, 7, 11216-11225.

(27) Zirbs, R.; Binder, W.; Gahleitner, M.; Machl, D. "Grafting From" -Living Cationic Polymerization of Poly(isobutylene) from Silica-Nanoparticle Surfaces. Macromol. Symp. 2007, 254, 93-96.

(28) Lassenberger, A.; Scheberl, A.; Stadlbauer, A.; Stiglbauer, A.; Helbich, T.; Reimhult, E. Individually Stabilized, Superparamagnetic Nanoparticles with Controlled Shell and Size Leading to Exceptional Stealth Properties and High Relaxivities. ACS Appl. Mater. Interfaces 2017, 9, 3343-3353.

(29) Gal, N.; Lassenberger, A.; Herrero-Nogareda, L.; Scheberl, A.; Charwat, V.; Kasper, C.; Reimhult, E. Interaction of Size-Tailored PEGylated Iron Oxide Nanoparticles with Lipid Membranes and Cells. ACS Biomater. Sci. Eng. 2017, 3, 249-259.

(30) Kurzhals, S.; Gal, N.; Zirbs, R.; Reimhult, E. Controlled Aggregation and Cell Uptake of Thermoresponsive PolyoxazolineGrafted Superparamagnetic Iron Oxide Nanoparticles. Nanoscale 2017, 9, 2793-2805.

(31) Bouchemal, K.; Mazzaferro, S. How to Conduct and Interpret ITC Experiments Accurately for Cyclodextrin-Guest Interactions. Drug Discovery Today 2012, 17, 623-629.

(32) Freire, E.; Mayorga, O. L.; Straume, M. Isothermal Titration Calorimetry. Anal. Chem. 1990, 62, 950A-959A.

(33) Chiad, K.; Stelzig, S. H.; Gropeanu, R.; Weil, T.; Klapper, M.; Müllen, K. Isothermal Titration Calorimetry: A Powerful Technique To Quantify Interactions in Polymer Hybrid Systems. Macromolecules 2009, 42, 7545-7552.

(34) Bouchemal, K. New Challenges for Pharmaceutical Formulations and Drug Delivery Systems Characterization Using Isothermal Titration Calorimetry. Drug Discovery Today 2008, 13, 960-972.

(35) Lassenberger, A.; Grünewald, T. A.; van Oostrum, P. D. J.; Rennhofer, H.; Amenitsch, H.; Zirbs, R.; Lichtenegger, H. C.; Reimhult, E. Monodisperse Iron Oxide Nanoparticles by Thermal Decomposition: Elucidating Particle Formation by Second-Resolved in Situ Small-Angle X-ray Scattering. Chem. Mater. 2017, 29, 4511-4522.

(36) Yuen, A. K. L.; Hutton, G. A.; Masters, A. F.; Maschmeyer, T. The Interplay of Catechol Ligands with Nanoparticulate Iron Oxides. Dalton Trans. 2012, 41, 2545-2559. 
(37) Napolitano, A.; d'Ischia, M.; Costantini, C.; Prota, G. A New Oxidation Pathway of the Neurotoxin 6-aminodopamine. Isolation and Characterisation of a Dimer with a Tetrahydro[3,4a]Iminoethanophenoxazine Ring System. Tetrahedron 1992, 48, 85158522.

(38) Bixner, O.; Lassenberger, A.; Baurecht, D.; Reimhult, E. Complete Exchange of the Hydrophobic Dispersant Shell on Monodisperse Superparamagnetic Iron Oxide Nanoparticles. Langmuir 2015, 31, 9198-9204.

(39) El-Faham, A.; Funosas, R. S.; Prohens, R.; Albericio, F. COMU: A Safer and More Effective Replacement for Benzotriazole-Based Uronium Coupling Reagents. Chem.—Eur. J. 2009, 15, 9404-9416.

(40) Mondini, S.; Ferretti, A. M.; Puglisi, A.; Ponti, A. Pebbles and PebbleJuggler: Software for Accurate, Unbiased, and Fast Measurement and Analysis of Nanoparticle Morphology from Transmission Electron Microscopy (TEM) Micrographs. Nanoscale 2012, 4, 53565372.

(41) Tellinghuisen, J. Isothermal Titration Calorimetry at Very Low c. Anal. Biochem. 2008, 373, 395-397.

(42) Tellinghuisen, J. Optimizing Experimental Parameters in Isothermal Titration Calorimetry: Variable Volume Procedures. J. Phys. Chem. B 2007, 111, 11531-11537.

(43) Gref, R.; Lück, M.; Quellec, P.; Marchand, M.; Dellacherie, E.; Harnisch, S.; Blunk, T.; Müller, R. H. "Stealth" Corona-Core Nanoparticles Surface Modified by Polyethylene Glycol (PEG): Influences of the Corona (PEG Chain Length and Surface Density) and of the Core Composition on Phagocytic Uptake and Plasma Protein Adsorption. Colloids Surf., B 2000, 18, 301-313.

(44) Moros, M.; Pelaz, B.; López-Larrubia, P.; García-Martin, M. L.; Grazú, V.; de la Fuente, J. M. Engineering Biofunctional Magnetic Nanoparticles for Biotechnological Applications. Nanoscale 2010, 2, $1746-1755$.

(45) Kurzhals, S.; Gal, N.; Zirbs, R.; Reimhult, E. Aggregation of Thermoresponsive Core-Shell Nanoparticles: Influence of Particle Concentration, Dispersant Molecular Weight and Grafting. J. Colloid Interface Sci. 2017, 500, 321-332.

(46) Schroffenegger, M.; Zirbs, R.; Kurzhals, S.; Reimhult, E. The Role of Chain Molecular Weight and Hofmeister Series Ions in Thermal Aggregation of Poly(2-Isopropyl-2-Oxazoline) Grafted Nanoparticles. Polymers 2018, 10, 451.

(47) Qin, X.; Chen, K.; Cao, L.; Zhang, Y.; Li, L.; Guo, X. Antifouling Performance of Nano-Sized Spherical Poly(N-hydroxyethyl acrylamide) Brush. Colloids Surf., B 2017, 155, 408-414.

(48) Cedervall, T.; Lynch, I.; Lindman, S.; Berggård, T.; Thulin, E.; Nilsson, H.; Dawson, K. A.; Linse, S. Understanding the Nanoparticle-Protein Corona Using Methods to Quantify Exchange Rates and Affinities of Proteins for Nanoparticles. Proc. Natl. Acad. Sci. U.S.A. 2007, 104, 2050-2055.

(49) Lindman, S.; Lynch, I.; Thulin, E.; Nilsson, H.; Dawson, K. A.; Linse, S. Systematic Investigation of the Thermodynamics of HSA Adsorption to $\mathrm{N}$-iso-Propylacrylamide/N-tert-Butylacrylamide Copolymer Nanoparticles. Effects of Particle Size and Hydrophobicity. Nano Lett. 2007, 7, 914-920.

(50) Bhattacharya, A.; Das, S.; Mukherjee, T. K. Insights into the Thermodynamics of Polymer Nanodot-Human Serum Albumin Association: A Spectroscopic and Calorimetric Approach. Langmuir 2016, 32, 12067-12077.

(51) Koshkina, O.; Westmeier, D.; Lang, T.; Bantz, C.; Hahlbrock, A.; Würth, C.; Resch-Genger, U.; Braun, U.; Thiermann, R.; Weise, C.; et al. Tuning the Surface of Nanoparticles: Impact of Poly(2-ethyl-2oxazoline) on Protein Adsorption in Serum and Cellular Uptake. Macromol. Biosci. 2016, 16, 1287-1300. 